\title{
Multiscale electrochemical analysis of the corrosion control of bronze in simulated acid rain by horse-chestnut (Aesculushippocastanum L.) extract as green inhibitor
}

\author{
Simona Varvara ${ }^{1, *}$, Giada Caniglia $^{2}$, Javier Izquierdo $^{2,3, * * *}$, Roxana Bostan $^{1}$, LuizaGăină ${ }^{4}$, \\ Otilia Bobis ${ }^{5}$, Ricardo M. Souto ${ }^{2,3}$ \\ ${ }^{1}$ Department of Exact Sciences and Engineering, "1 Decembrie 1918" University of Alba Iulia, \\ 15-17 Unirii St., 510009 Alba-Iulia, Romania \\ ${ }^{2}$ Department of Chemistry, Universidad de La Laguna, P.O. Box 456, E-38200 La Laguna \\ (Tenerife), Spain \\ ${ }^{3}$ Institute of Materials and Nanotechnology, Universidad de La Laguna, P.O. Box 456, E-38200 \\ La Laguna (Tenerife), Spain \\ ${ }^{4}$ Department of Organic Chemistry, "Babes-Bolyai" University, 11 Arany Janos St., 400028 \\ Cluj-Napoca, Romania \\ ${ }^{5}$ Life Science Institute, Apiculture and Sericiculture Department, University of Agricultural \\ Sciences and Veterinary Medicine, 3-5 Manastur St., 400028 Cluj-Napoca, Romania
}

\begin{abstract}
Horse-chestnut ethanolic extract was tested as potential corrosion inhibitor of bronze in simulated acid rain. The extract was analysed by FTIR, GC-MS and HPLC-PDA, and its anticorrosion behaviour studied using a multiscale electrochemical approach (polarization curves, EIS and scanning electrochemical microscopy), along with SEM-EDS. 94\% inhibition efficiency was attained by developing a surface physisorbed film. A novel methodology for kinetic evaluation of dynamic adsorption of inhibitive species on metal surface is proposed using SECM, achieving good agreement with results from conventional electrochemical techniques. Excellent adsorption-desorption kinetic constants $\left(k_{\mathrm{a}}=0.102 \mathrm{~s}^{-1} \mathrm{~mol}^{-1} \mathrm{~L} ; k_{\mathrm{d}}=3.33 \times 10^{-5} \mathrm{~s}^{-1}\right)$ were determined.
\end{abstract}

Keywords: bronze; EIS; scanning electrochemical microscopy; potentiodynamic polarization; adsorption isotherms; corrosion inhibition. 


\section{Introduction}

Copper-tin alloys commonly named bronzes are some of the earliest metallic materials known by mankind and they were used to produce weapons, tools, statues and ornaments [1]. Due to their excellent electrical and thermal conductivities, hardness and corrosion resistance, bronzes continue to have widespread applications in various industrial fields, such as building construction, marine, electronics and electricity, as well as for decorative purposes, artworks and coinage.

In humid atmosphere, bronzes tend to spontaneously passivate by the formation of copper oxides (namely, cuprite and tenorite) layers on their surfaces [2-4]. Once formed, these oxidised layers often called patina are rather stable acting as protective barriers to the metallic surface under various exposure conditions [5,6]. Nevertheless, in aggressive environments, such as water containing carbonates, sulphates, chlorides or nitrates, corrosion may restart even under the patina, leading to a fast degradation of the bronze surface [7-10]. To overcome this destructive phenomenon, different protection methods have been developed [3,11-13].

The use of organic inhibitors to prevent bronze corrosion has been studied extensively [14-16], since it is simpler and less expensive than other procedures. Typical organic molecules used for bronzes protection include benzotriazole and its derivatives [17,18], substituted imidazoles [19-21], triazole [22,23] and thiadiazole derivatives [12,24-26], Schiff bases [27], and amino acids [28,29]. Despite their excellent anticorrosive properties, many of these organic inhibitors are rather expensive and some have been proved to be hazardous for aquatic and animal life.

Due to the increasing awareness of human health and environmental protection, the development of new effective 'green' alternatives to the synthetic corrosion inhibitors has become mandatory. Most of the environmental-friendly corrosion inhibitors reported in recent years are based on naturally-produced plant extracts because they are biodegradable, cheap, readily available at large scale, and renewable sources of materials [30]. In addition, plant extracts are considered a rich source of naturally synthesized chemical compounds that can be extracted using quite simple and economically feasible procedures. It was found that the inhibition performance of plant extracts is usually ascribed to the presence of complex compounds in their composition, including tannins, flavonoids, alkaloids, phenolics, nitrogen bases, carbohydrates, proteins and amino acids, as well as hydrolysis products. These natural 
organic compounds contain heteroatoms (i.e., $\mathrm{O}, \mathrm{S}$, and $\mathrm{N}$ ), aromatic rings and conjugated double bonds, which could act as adsorption centres to the metallic surface [30].

Although various plant extracts have been proposed to be efficient green corrosion inhibitors for copper [31-36] and brass [37-40] in different environments, their inhibition potential on bronze corrosion has been scarcely investigated. In a recent paper, Benzidia et al. [41] studied the influence of the tannin extract from the green rind of Aloe Vera on B66 bronze corrosion in $3 \% \mathrm{NaCl}$. An inhibition efficiency of $89 \%$ was achieved using $150 \mathrm{ppm}$ tannin extract. Channouf et al. [42] showed that Juniperus communis presents some anticorrosive properties on $\mathrm{Cu} 10 \mathrm{Sn}$ bronze in $0.5 \mathrm{M} \mathrm{NaCl}$ solution. The use of the methanolic extract of Salvia hispanica (S. hispanica) seeds as a green corrosion inhibitor for bronze in a simulated acid rain solution was reported by Larios-Galvez et al. [43]. They found that Salvia hispanica extract acts as an anodic type-inhibitor, presenting a maximum effectiveness of $96 \%$ at 400 ppm.Besides plant extracts, the bee products, namely propolis [44] and honey [45] were also proved as efficient green inhibitors of bronze corrosion.

The present research focuses on the application of the alcoholic extract of horse chestnut seeds (Aesculushippocastanum L.) as a potential non-toxic corrosion inhibitor for bronze in a weakly acidic solution containing $\mathrm{Na}_{2} \mathrm{SO}_{4}$ and $\mathrm{NaHCO}_{3}(\mathrm{pH}$ ), simulating an acid rain in the urban environment. Aesculushippocastanum L. is a species of flowering plant in the soapberry and lychee family Sapindaceae. It is native to small areas of the mixed forests in the Pindus Mountains and the Balkans (South East Europe), although nowadays the horse-chestnut trees are often found in many parks and cities all over the world. Horse chestnut extracts present high antioxidant properties, as well as antibacterial, antimicrobial, antiviral, and antifungal effects, therefore acting as environmentally biocompatible phototherapeutics [46]. Previously, the alcoholic extract of horse chestnut seeds was successfully used as levelling agent in copper electrowinning from acidic copper sulphate solution [47], and for lead electrodeposition from Betts-type electrolytes [48]. More recently, the water extract of horse-chestnut fruit was proved to be rather effective inhibitor of St3 steel corrosion in tap water [49].

In this paper, the anticorrosive properties of the ethanolic extract of horse chestnut (HCE) on bronze corrosion were investigated by electrochemical methods, i.e. potentiodynamic polarization and electrochemical impedance spectroscopy, as well as by scanning electrochemical microscopy (SCEM) technique. Several factors were studied, such as inhibitor 
concentration, immersion time and temperature to assess the best conditions for the inhibition performance of the horse chestnut extract. In addition, the bronze surface was also examined by scanning electron microscopy coupled to energy dispersive X-ray spectrometry (SEM-EDS) to obtain morphological and chemical composition information of the metal-inhibitor system, whereas Fourier-transform infrared spectroscopy (FTIR), gas chromatography-mass spectrometry (GC-MS), and high performance liquid chromatography (HPLC)analyses were used to characterize the extract employed as corrosion inhibitor. The multiscale electrochemical approach herein employed has shown to be very powerful for the characterization of the surface interactions heterogeneously and dynamically evolving throughout the metal surface, associated to inhibitor adsorption and deriving adsorption isotherms. The estimation of the quantitative kinetic and thermodynamic parameters, along with the evaluation of the surface distribution upon interaction of the inhibitor, effectively provided complementary and consistent data. To our knowledge, this is the first time that such quantitative information on adsorption phenomena with metal-inhibitor systems is achieved using SECM.

\section{Experimental}

\subsection{Inhibitor preparation}

Fresh fruits of Aesculushippocastanum L. were collected from a park area in ClujNapoca, Romania in September 2016. The exterior wooden shells were removed and the nut-like seeds (called conkers or horse-chestnuts) were collected. The horse-chestnut seeds were cleaned using distilled water and stored for three months in a dark and dry environment, at room temperature. After that, the dried horse-chestnut seeds were crushed in an agate mortar and a powder-like material was obtained. $10 \mathrm{~g}$ of powdered horse-chestnuts were extracted in $100 \mathrm{~mL}$ of absolute ethanol, in a Soxhlet system for $4 \mathrm{~h}$. The ethanolic extract of horse-chestnut was filtered and centrifuged to remove the traces of solid suspension and it was next evaporated under reduced pressure at $40^{\circ} \mathrm{C}$. Finally, a dark brown almost solid residue was collected and stored at low temperature in a refrigerator. The residual moisture content $(8.63 \%)$ was determined before HCE usage.

\subsection{Chemicals and materials}


Analytical grade reagents (Merck, Darmstadt, Germany) and ultra-pure water (Millipore, $18 \mathrm{M} \Omega \mathrm{cm}$ ) were employed to prepare the corrosive blank electrolyte, consisting of an aqueous solution of $0.2 \mathrm{~g} \mathrm{~L}^{-1} \mathrm{Na}_{2} \mathrm{SO}_{4}$ and $0.2 \mathrm{~g} \mathrm{~L}^{-1} \mathrm{NaHCO}_{3}$, acidified to $\mathrm{pH} 5$ by addition of dilute $\mathrm{H}_{2} \mathrm{SO}_{4}$. Various amounts of horse chestnut extract were dissolved in the blank corrosive electrolyte in the concentration range of $0.1 \mathrm{~g} \mathrm{~L}^{-1}$ to $1 \mathrm{~g} \mathrm{~L}^{-1}$ (w/v).

The chemical composition of the bronze was as follows (wt. \%): Cu-94.03; $\mathrm{Sn}-3.31$; $\mathrm{Pb}-$ 0.24; Zn-1.44; Ni-0.25; Fe-0.22 and S-0.51. Prior to each measurement, the bronze surface was mechanically abraded using successively 800, 1200 and 4000 grit SiC papers, and finished with $0.3 \mu \mathrm{m}$ alumina slurry resulting in a mirror-like surface. The bronze substrate was then ultrasonically cleaned in ethanol, thoroughly rinsed with water and dried in air.

Phenolic acids and flavonoids (3,4-dihydroxybenzoic acid and quercetin, kaempferol, myricetin-3-rhamnozide, quercetin rhutinozide, quercetin-3-rhamnozide) were purchased from Karl-Roth (Karlsruhe, Germany), Sigma-Aldrich (St. Louis, USA) and Fluka (Buchs, Switzerland). Folin Ciocâlteu reagent, aluminium chloride, sodium carbonate were purchased from Sigma-Aldrich (St. Louis, USA). Analytical grade solvents were used for HPLC and spectrophotometric determinations. Deionized water $\left(0.067 \mu \mathrm{S} \mathrm{cm} \mathrm{cm}^{-1}\right)$ was produced with a Millipore Milli-Q assembly.

\subsection{Conventional electrochemical measurements}

All conventional electrochemical measurements were performed in a three-electrode configuration cell. A cylindrical bronze specimen with an exposed area of $0.28 \mathrm{~cm}^{2}$ was used as working electrode for the conventional electrochemical investigations. A large platinum grid and a saturated calomel electrode (SCE) were used as auxiliary and reference electrodes, respectively. The corrosion tests were carried out using $100 \mathrm{~mL}$ of the electrolytes, under nonstirred and naturally aerated conditions.

Electrochemical impedance spectroscopy and potentiodynamic polarization measurements were carried out using a Princeston Applied Research potentiostat model 2273. Before each electrochemical test, the bronze sample was left unpolarized in the electrolyte for 1-h to attain a stationary open circuit potential value.

Electrochemical impedance spectroscopy measurements (EIS) were performed at the open circuit potential, in the frequency range from $10 \mathrm{kHz}$ to $10 \mathrm{mHz}$ with 5 points per hertz 
decade and an $a c$ voltage amplitude of $\pm 10 \mathrm{mV}$. To assess the time-stability of the HCE inhibitive properties on bronze, $a c$ impedance experiments were performed at different immersion times up to $36 \mathrm{~h}$. The obtained impedance data were modelled using ZSimpWin 3.21 software.

Polarization curves were recorded at constant sweep rate of $10 \mathrm{mV} \mathrm{min}^{-1}$, in a wide potential range of $\pm 200 \mathrm{mV} v \mathrm{~s}$. the open circuit potential, starting from the cathodic to the anodic direction. The sealed electrochemical cell was thermostatted at various temperatures, namely 298, 308, 318 and $328 \mathrm{~K}$.

\subsection{Scanning Electrochemical Microscopy (SECM)}

SECM experiments were conducted using a scanning electrochemical microscope from Sensolytics GmbH (Bochum, Germany). The SECM probe was a home-made platinum microelectrode with a platinum disk of $12.5 \mu \mathrm{m}$ diameter. Microelectrodes were fabricated following well-established procedures [50]. For this process, the components were borosilicate glass capillaries of dimensions $1.5 \mathrm{~mm}$ outer diameter and $0.375 \mathrm{~mm}$ glass wall from Hilgenberg GmbH (Massfeld, Germany), $12.5 \mu \mathrm{m}$ diameter platinum wire from Goodfellow (Cambridge, UK), two-component conductive silver epoxy from RS Components (Corby, UK), and conductive copper wire, assisted with a Beveller heat pipette-puller from Sutter (Novato, CA, USA). The fabrication routine and the heat-pulling of the capillaries were optimized to produce microelectrodes with a cone-shape end. All SECM measurements were done with microelectrodes presenting an RG ratio (i.e., ratio between the diameters of the Pt micro disk and the surrounding glass) equal to 40 .

The small electrochemical cell employed for the SECM measurements consisted of a bronze sample of flat $1.44 \mathrm{~cm}^{2}$ area. Control on this area preventing electrolyte-metal contact at the sides of the sample was established once the target was embedded in epoxy resin (Buhler, Epoxycure $^{\mathrm{TM}}$ ) to avoid electrolyte penetration, and this was placed at the bottom of the small electrochemical cell facing upwards. The auxiliary and the reference electrodes were a platinum wire and an $\mathrm{Ag} / \mathrm{AgCl} / \mathrm{KCl}$ (sat.) electrode, respectively. Ferrocene-methanol (Fc-OH) was employed as redox mediator for the amperometric feedback operation of SECM. $1 \mathrm{mM} \mathrm{Fc-OH}$ was added to the test electrolytes, and the tip was biased at $+0.50 \mathrm{~V}$ vs. $\mathrm{Ag} / \mathrm{AgCl} / \mathrm{KCl}$ (sat.) to ensure the electro-oxidation of ferrocene-methanol under diffusion-controlled conditions. 
Following concerns regarding the possible blockage of the microelectrode surface (fouling) by corrosion products arising from the reactions occurring at the copper alloy [51], the surface condition of the $\mathrm{Pt}$ microelectrode was continuously monitored and eventually regenerated. This effect was circumvented in this work by performing short-duration scans (5 min for each 2-D measurements), and by mechanically polishing the SECM probe every time the control CV exhibited a distorted sigmoid shape. The short duration condition was achieved by adjusting the scan rate at $25 \mu \mathrm{m} \mathrm{s}^{-1}$ with $50 \mu \mathrm{m}$ resolution, as a compromise to perform shortlasting scans providing surface information before eventual fouling of the microdisk, without excessively speeding the movement of the probe to avoid convective effects. It must be noticed that the procedure employed to assure the reproducibility of the Pt microelectrode was performed without removing it from the tip holder, and therefore its position with respect to the surface under study kept under control.

\subsection{Chemical and morphological analyses}

The characterization of the bronze surface was performed after immersion of the electrodes during 24-h in the corrosive solutions both in the absence and in the presence of HCE at desired concentration. Then, the specimens were washed gently with water, carefully dried and characterized without any further treatment by SEM-EDS. SEM measurements were performed using a JEOL JSM 5600 LV microscope, while the chemical analysis of the surface was performed by EDS using an Oxford Instruments spectrometer (INCA 200 software). The energy of the acceleration beam was $15 \mathrm{kV}$.

The characterization of HCE was conducted by Fourier Transform-Infrared (FT-IR) spectroscopy, gas chromatography-mass spectrometry (GC-MS), and high-performance liquid chromatography, photo diode array detection (HPLC-PDA) measurements. FT-IR absorption spectrum of the horse chestnut extract was recorded in $\mathrm{KBr}$ pellet with a Bruker Vector $22 \mathrm{FT}-$ IR spectrometer from 4000 to $600 \mathrm{~cm}^{-1}$. GC-MS was recorded on Agilent 2010 PLUS Mass Spectrometer coupled with Gas Chromatograph equipped with a Carbowax type column (30 $\mathrm{m} \times$ $0.32 \mathrm{~mm}$ ID and $0.50 \mu \mathrm{m}$ film thicknesses). Helium at a flow rate of $0.7 \mathrm{~mL} \mathrm{~min}^{-1}$ was used as the carrier gas, and $1 \mu \mathrm{L}$ sample was injected. The analysis was performed as follows: injector temperature $250^{\circ} \mathrm{C}$, the ion source temperature $220^{\circ} \mathrm{C}$, and the interface temperature $250^{\circ} \mathrm{C}$. The column temperature program was the following: the initial temperature was $40^{\circ} \mathrm{C}$ and it was 
maintained for $5 \mathrm{~min}$, subsequently increased to $220^{\circ} \mathrm{C}$ at a rate of $4^{\circ} \mathrm{C} \mathrm{min}^{-1}$, and then it was held at $220^{\circ} \mathrm{C}$ for $15 \mathrm{~min}$. The electron impact (EI) was set at $70 \mathrm{eV}$. A mass range of 35-500 $\mathrm{m} / \mathrm{z}$ was recorded at one scan per second. The chemical species were identified using the Wiley Registry of mass spectra databases (WILEY Library $8 \mathrm{~L}$ ).

The dark-brown solid resin (concentrated alcoholic extract of Aesculushippocastanum) used in the present study ( $2 \mathrm{~g}$ of solid resin), was dissolved in $50 \mathrm{ml}$ ethanol $(80 \% \mathrm{v} / \mathrm{v})$ to give a $4 \%$ solution $(\mathrm{m} / \mathrm{v})$. The obtained extract was used for spectrophotometric determinations (total polyphenolic content and flavonoid content) and HPLC-PDA determinations of individual phenolics.

Total soluble phenolic compounds from the extract were determined with Folin-Ciocâlteu reagent according to the method of Singleton et al. [52] with some modifications. A volume of $0.5 \mathrm{~mL}$ extract, was placed in a glass tube and $2.5 \mathrm{~mL}$ Folin-Ciocâlteu reagent (diluted 1:10) was added and after $5 \mathrm{~min}, 3 \mathrm{~mL}$ of $7.5 \%(\mathrm{w} / \mathrm{v})$ sodium carbonate was also added. The tubes were incubated in the dark for $2 \mathrm{~h}$ at room temperature and the absorbance of the mixture was read at $760 \mathrm{~nm}$ against a blank consisting of methanol, Folin-Ciocâlteu reagent and sodium carbonate. For the calibration curve, a stock solution of gallic acid $1 \mathrm{mg} \mathrm{mL}^{-1}$ was used, serial dilutions $\left(0.005-0.1 \mathrm{mg} \mathrm{mL}^{-1}\right)$ were made and subjected to the same protocol. The calibration curve equation for calculating the amounts of polyphenols was $y=8.48752 x+0.02576$, with $R^{2}=0.9965$. The results were expressed as gallic acid equivalents.

The flavone/flavonol content was determined using a method adapted by Arvonet-Grand et al. [53] using a standard curve of quercetin $\left(0.001-0.04 \mathrm{mg} \mathrm{mL}^{-1} ; y=47.66539 x-0.01857 ; R^{2}\right.$ $=0.99712$ ). In brief, $3 \mathrm{~mL}$ of diluted extract was placed in a glass tube and the same amount of $5 \%$ aluminium chloride was added, mixed thoroughly and placed in the dark for $30 \mathrm{~min}$. Absorbtion readings were made at $415 \mathrm{~nm}$ using a Pharmaspech UV-1700, Shimadzu spectrophotometer (Kioto, Japan) against a blank sample containing methanol and $\mathrm{AlCl}_{3}$ solution. The flavonoid content was expressed as mg of quercetin equivalents. A Shimadzu LC10ADVP system (Kioto, Japan), consisting of SCL-10AVP system controller, SPP-M20A Prominence Diode Array Detector, LC-10ADSP binary pumps, CTO-10AVP column oven and SIL-10AF autosampler, was used for separation of individual phenolics. Separation was carried out on a Supelcosil LC-18 column $(250 \mathrm{~mm} \times 4.6 \mathrm{~mm}, 5 \mu \mathrm{m})$, using as mobile phases methanol:acetic acid: $\mathrm{H}_{2} \mathrm{O}$ 10:2:88 (solvent A) and methanol:acetic acid: $\mathrm{H}_{2} \mathrm{O}$ 90:3:7 (solvent B), 
using the following linear gradient of A-B: $10 \mathrm{~min}, 85: 15 ; 30 \mathrm{~min}, 50: 50 ; 45 \mathrm{~min}, 15: 85 ; 55$ min, 100:0 (total run time, $60 \mathrm{~min}$ ). Phenolic acids and flavonoids chromatograms were registered at 254, 270, 320 and $340 \mathrm{~nm}$. Co-chromatography with standards was also performed, for identification of phenolic compounds from the sample. The concentrations of each individual compound was determined based on external standard method, using calibration curves of each compound, after comparing the retention time and UV spectra with reference standards.

\section{Results and discussion}

3.1. Fourier transform infrared spectroscopy measurements, gas chromatography-mass spectrometry and high-performance liquid chromatography characterization

FTIR spectroscopy, GC-MS and HPLC were used to chemically identify the components of the HCE and their functional groups. The obtained GC-MS and HPLC-PDA chromatograms are shown in Figure 1.Aesculushippocastanumseedsextract contain a complex chemical composition, polysaccharides (both starches and non-starches), proteins, lipids, mineral salts, saponin also named escins, flavonoids and many minor components. The molecular structures of several organic compounds identified in HCE by GC-MS are listed in Table 1, depicting a complex chemical composition involving saturated and unsaturated aliphatic acids, esters, alcohols and heterocyclic derivatives.

As shown in Figure 1B, the ethanolic extract of horse chestnut also possess high amounts of biologically active compounds from the class of polyphenols and different classes of flavonoids (flavones/flavonols, flavanones/dihydroflavonols, or other phenols). The characteristic compounds identified in the horse-chestnut extract by HPLC-PDA and their concentrations are presented in Table 2. The total phenolic content of the alcoholic extract of horse chestnut was $2.53 \%$ and $1.01 \%$ flavone/flavonol content, similar to other studies $[54,55]$. One phenolic acid was identified and quantified (3,4-dihydroxibenzoic acid) as well as six flavonoids (myricetin-3-rhamnozide, quercetin-3-glucozide, quercetin-rutinozide, quercetin-3rhamnozide, quercetin and kaempherol). The highest amounts of flavonoids were two quercetin glycosides (quercetin-3-glucozide (114.99 ppm) and quercetin-3-rhamnozide (89.69 ppm).

The FTIR spectrum of the horse-chestnut extract is given in Figure 2.The most abundant compounds presented in HCE contain functional groups (i.e., hydroxyl, carbonyl, ester) and 
heterocycles, as well as unsaturated rings, which could act as adsorption centres on metallic surfaces. Phenolic acids and flavonoids (both aglycones and glycosides), present this characteristic, due to the presence of hydroxyl groups and heterocycles from their structure. Broad absorption peak was found between 3000 and $3700 \mathrm{~cm}^{-1}$ in the FTIR spectra, corresponding to the free and associated stretching vibration of $\mathrm{OH}$ groups from starches-based matrix, carbohydrate and other constituents from the HCE. The main ester and fatty acids responsible for the vibrations observed in the FT-IR spectrum include the symmetrical and asymmetrical stretching vibration of the alkyl units, $v\left(\mathrm{CH}_{2}\right) 2854 \mathrm{~cm}^{-1}$ and $2925 \mathrm{~cm}^{-1}$; the bending vibration of the methyl units, $\delta\left(\mathrm{CH}_{3}\right) 1465 \mathrm{~cm}^{-1}$; the carbonyl stretching vibration at the expected position, $v(\mathrm{C}=\mathrm{O}) 1744 \mathrm{~cm}^{-1}$ and a characteristic vibration for ester $v(\mathrm{C}-\mathrm{O}) 1376 \mathrm{~cm}^{-1}$. Finally, the unsaturated fatty acids methyl linoleate and methyl elaidate and others seem to be responsible for the stretching vibration $v(\mathrm{C}=\mathrm{C}) 1651 \mathrm{~cm}^{-1}$.

\subsection{Corrosion studies}

\subsubsection{Polarization curve measurements}

The polarization curves for bronze were recorded in $0.2 \mathrm{~g} \mathrm{~L}^{-1} \mathrm{Na}_{2} \mathrm{SO}_{4}+0.2 \mathrm{~g} \mathrm{~L}^{-1}$ $\mathrm{NaHCO}_{3}(\mathrm{pH}$ 5) solution with and without HCE. The effect of HCE concentration on the polarisation behaviour of bronze was first recorded at $298 \mathrm{~K}$ and it is presented in Figure 3. It was found that the addition of HCE to the corrosive solution shifted both the cathodic and the anodic curves towards lower current densities values as compared to those obtained in the inhibitor-free solution. This trend was more pronounced as the concentration of HCE increased from $0.1 \mathrm{~g} \mathrm{~L}^{-1}$ to $0.5 \mathrm{~g} \mathrm{~L}^{-1}$; beyond that, the current density values slightly increase at higher concentrations of inhibitor, but they remained lower with respect to uninhibited solution.

Compared to the anodic curves, the shift of the cathodic curves with HCE concentration is less apparent. Thus, it can be inferred that HCE is able to retard to some extent both electrochemical reactions, i.e. the cathodic oxygen reduction and the anodic bronze dissolution, with a predominant control on the anodic reaction.

Quantitative information on the kinetics of the corrosion process was derived by determining the characteristic electrochemical parameters from the Tafel extrapolation of the polarization curves, namely the corrosion current density $\left(j_{\text {corr }}\right)$, the corrosion potential $\left(E_{\text {corr }}\right)$, 
and the cathodic $\left(-\beta_{\mathrm{c}}\right)$ and anodic $\left(\beta_{\mathrm{a}}\right)$ Tafel slopes, given in Table 3. Inhibition efficiency $(z)$ values calculated according to equation (1) are also presented in Table 3.

$$
z(\%)=\frac{j_{\text {corr }}^{0}-j_{\text {corr }}}{j_{\text {corr }}^{0}} \times 100
$$

where with and without HCE, respectively.

The results given in Table 3 show a decrease of $j_{\text {corr }}$ values in the presence of HCE, and the lowest value was obtained in the solution containing $0.5 \mathrm{~g} \mathrm{~L}^{-1} \mathrm{HCE}$. By increasing the HCE concentration, the $j_{\text {corr }}$ values are slightly higher than in the case of $0.5 \mathrm{~g} \mathrm{~L}^{-1}$. Accordingly, the inhibition efficiency attains its maximum value of $87.5 \%$ in the presence of $0.5 \mathrm{~g} \mathrm{~L}^{-1} \mathrm{HCE}$. As shown in Table 3, the addition of higher HCE concentrations up to $1 \mathrm{~g} \mathrm{~L}^{-1}$ did not improve the inhibition efficiency for bronze protection.

The decrease of $j_{\text {corr }}$ values in the presence of HCE might be ascribed to the adsorption of the organic compounds from HCE on bronze, through the oxygen atoms in their functional groups (i.e. $\mathrm{O}-\mathrm{H}, \mathrm{C}-\mathrm{OH}, \mathrm{C}=\mathrm{O}$ ) and the aromatic rings with the consequent formation of an insulating layer, which blocks the active reaction sites on the metal surface.

No definite trend was observed in the shifts of $E_{\text {corr }}$ values at different HCE concentrations. However, all the displacements were smaller than $85 \mathrm{mV}$, which supports the idea that the horse chestnut extract behaves as a mixed-type inhibitor. It is also worth mentioning that $\beta_{\mathrm{a}}$ values substantially increased when HCE was added to the corrosive medium, while simultaneously the $-\beta_{\mathrm{c}}$ values were less affected by the presence of the inhibitor. These changes of the Tafel slopes further reveal that HCE suppresses both electrochemical reactions by adsorbing on the bronze surface, but the anodic suppression plays a dominant role in this process $[26]$.

The effect of temperature was further investigated. Since temperature is an important factor that affects the metals corrosion behaviour and change the adsorption strength of the inhibitors on metal surfaces $[33,42]$, the effect was next studied using polarization measurements. Several changes might occur on the metallic surface with temperature increasing, such as rapid etching and desorption of the inhibitor or even the decomposition of the inhibitor [56]. In order to gain more information about the type of adsorption and the anticorrosive effectiveness of the HCE at higher temperatures, polarization measurements were performed in 
$0.2 \mathrm{~g} \mathrm{~L}^{-1} \mathrm{Na}_{2} \mathrm{SO}_{4}+0.2 \mathrm{~g} \mathrm{~L}^{-1} \mathrm{NaHCO}_{3}$ (pH 5) solution in the absence and in the presence of $\mathrm{HCE}$ at various temperatures in the range from $298 \mathrm{~K}$ to $328 \mathrm{~K}$. The solution $\mathrm{pH}$ slightly varied when increasing the temperature. Thus, experiments conducted at $328 \mathrm{~K}$ showed $\mathrm{pH} 5.45$, whereas the inhibitor-containing solutions exhibited $\mathrm{pH}$ 5.18. Such minor $\mathrm{pH}$ variations did not disturb significantly the expected linearity in the Arrhenius plot. The experimental results are depicted in Figures 3 and 4, and the values of the associated electrochemical parameters from Tafel extrapolation and $z(\%)$ for all the HCE concentrations are summarized in Tables 3 and 4.

Table 4shows that the temperature raising leads to a decrease of the $j_{\text {corr }}$ values for uninhibited and inhibited solutions, as well. However, the values of $j_{\text {corr }}$ obtained in the presence of $\mathrm{HCE}$ at high temperatures are lower with respect to the blank solution, indicating that $\mathrm{HCE}$ exhibits some inhibiting properties at all studied temperatures.

The anticorrosive efficiency of HCE on bronze decreases gradually with the temperature increase (Tables 3 and 4). Nevertheless, in the presence of the 'optimum' concentration of inhibitor $\left(0.5 \mathrm{~g} \mathrm{~L}^{-1}\right)$, the $z(\%)$ value is rather high even at $328 \mathrm{~K}$, accounting around $73.1 \%$. The increase of the corrosion rates with the temperature was noticed for other natural corrosion inhibitors [32-36,39,40,42]. This behaviour could be explained by partial desorption [32$34,36,39,40]$ or even decomposition of the HCE at high temperatures, resulting in a lower coverage of the bronze surface.

To further understand the kinetics of corrosion inhibition process in the presence of HCE, the activation parameters were calculated from Arrhenius and transition state equations $[33,56]$ :

$$
i_{\text {corr }}=k \exp \left(-\frac{E_{\mathrm{a}}}{R T}\right)
$$

$$
k_{\text {rorr }}=\frac{R T}{N h} \exp \left(\frac{\Delta S_{G}}{R}\right) \exp \left(-\frac{\Delta H_{G}}{R T}\right)
$$

where $k$ is the Arrhenius pre-exponential factor, $E_{\mathrm{a}}$ the activation corrosion energy, $R$ the universal gas constant, $T$ the absolute temperature, $h$ the Planck's constant, $N$ the Avogadro's number, $\Delta S_{\mathrm{a}}$ the entropy of activation, $\Delta H_{\mathrm{a}}$ the enthalpy of activation, and $j_{\text {corr }}$ is the corrosion current density, which is directly related to rate of metal dissolution reaction [56,57].

Figure 5Adepicts the Arrhenius plots for bronze corrosion in the absence and in the presence of $\mathrm{HCE}$ at different concentrations. The calculated $E_{\mathrm{a}}$ values are listed in Table 4. Inspection of the data in Table 4 evidences that $E_{\mathrm{a}}$ values obtained in the presence of HCE are 
higher than in its absence, which could be associated to a physical adsorption process of the inhibitor on the bronze surface that occurs in the first stage, in accordance with previously reported results $[32-34,36,39,40]$. Hence, the presence of the inhibitor kinetically hinders the bronze degradation due to the eventual adsorption of the organic compounds, which prevent the occurrence of the electrochemical reactions at the surface. According to the literature $[33,34,39]$, the increase in $j_{\text {corr }}$ in warmer environments might be attributed to a decrease of the inhibitor adsorption on the metallic surface as the temperature increases, resulting in larger metal areas exposed to the corrosive solution.

On the other hand, Figure 5B shows the plots of $\ln \left(j_{\text {corr }} / T\right)$ against $1 / T$ for the blank and with different concentrations of inhibitor. Straight lines were obtained with a slope of $\left(-\Delta H_{\mathrm{a}} / R\right)$ and an intercept of $\left[\ln (R / N h)+\Delta S_{\mathrm{a}} / R\right]$, from which the values of $\Delta H_{\mathrm{a}}$ and $\Delta S_{\mathrm{a}}$ were calculated and included in Table 4. The positive signs of the activation enthalpies, $\Delta H_{\mathrm{a}}$ indicate that the dissolution process of bronze is endothermic in nature [56], whereas the negative values for $\Delta S_{\mathrm{a}}$ in uninhibited and inhibited solutions indicate that the formation of the activation complex in the rate determining step represents an association rather than a dissociation step, meaning that a decrease in disorder takes place during the course of the transition from reactants to the activated complex [32].

\subsubsection{Electrochemical impedance spectroscopy measurements}

In order to assess the time evolution of the inhibitive layer performance of the HCE during time, EIS measurements were performed at different exposure periods up to $36 \mathrm{~h}$ in $0.2 \mathrm{~g}$ $\mathrm{L}^{-1} \mathrm{Na}_{2} \mathrm{SO}_{4}+0.2 \mathrm{~g} \mathrm{~L}^{-1} \mathrm{NaHCO}_{3}(\mathrm{pH}$ 5) solution without and with the addition of $\mathrm{HCE}$ at various concentrations. The first impedance measurement was carried out after 1-h stabilization period at 298 K. Subsequently, the impedance spectra were collected every $2 \mathrm{~h}$.

Figure 6 shows typical examples of impedance spectra represented as Nyquist diagrams and Bode plots measured on the corroding bronze electrode at different immersion times in the uninhibited bronze and in bronze exposed to the HCE-containing solutions. The impedance diagrams are characterized by a flattened semi-circular shape with capacitive loops in the entire frequency domain. The diameters of the capacitive loops obtained in the presence of HCE were larger than for uninhibited solution, which confirms the anticorrosive properties of the studied inhibitor. 
The impedance spectra of bronze obtained in the blank electrolyte consisted of tworelaxation constants, and the equivalent electrical circuit composed of two ladder parallel $R-Q$ circuits depicted in Figure 7A was used to reproduce the experimental data and to extract the corresponding $R-Q$ parameters. As the loops in the impedance diagrams are depressed semicircles, constant phase elements (CPE), represented by the terms $Q$ and $n$, were used instead of capacitances to compensate for the surface roughness and other inhomogeneities, the adsorption of the inhibitor and the variations in the composition and properties of the surface layers. The impedance of the CPE is defined as [58]:

$$
Q=Z_{\mathrm{CPE}(\omega)}=\left[c(j \omega)^{n} \mathbf{T}^{-1}\right.
$$

where $Q$ is the constant of the CPE element, $j$ is the imaginary number, $\omega$ is the angular frequency and $n$ is the exponent which defines the character of frequency-dependence $(-1 \leq n \leq$ 1).

The obtained fitted curves have been plotted as crosses in the Nyquist diagrams and lines in the Bode diagrams, and they are shown together with the experimental data represented by symbols in the spectra shown in Figure 6. It can be observed that the experimental and the calculated impedance data superimposed almost perfectly on each other, demonstrating the validity of the equivalent electrical circuits adopted for the simulation of the electrochemical impedance data. In our study, the values of the $n$ exponent in the CPE analytical expressions used for fitting the depressed features of the experimental impedance ranged $0.50-0.99$, an interval similar to other reported results [27], reflecting intermediate behaviour between a capacitor and a resistor.

By following several reported studies [13,19,59], a physical interpretation of the circuit elements can be given as follows: $R_{\mathrm{e}}$ is the solution resistance, $R_{\mathrm{ct}}$ and $Q_{\mathrm{dl}}$ are parameters describing the charge transfer process at the bronze/electrolyte interface, while the low frequency elements, $R_{\mathrm{F}}$ and $Q_{\mathrm{F}}$ refers to an oxidation-reduction process taking place at the electrode surface, involving the surface corrosion products (possibly related to the redox reaction between $\mathrm{Cu}$ and $\mathrm{Cu}(\mathrm{I}))$.

In the presence of HCE, three capacitive loops, though badly separated each other are necessary for the computer fitting of experimental data. The corresponding equivalent circuit with three-time constants given in Figure 7B contains an additional $R_{\mathrm{f}}-Q_{\mathrm{f}}$ couple that is observed in the high-frequency domain and can be ascribed to the formation of a thin surface film by the 
adsorbed inhibitor. $R_{\mathrm{f}}$ represents the resistance towards the access of ions through the pores of the surface film, and $Q_{\mathrm{f}}$ corresponds to the capacitance of the surface film. The values of the pseudo-capacitances $(C)$ associated with each of the CPE's were recalculated using the equation [60]:

$$
C=\left(R^{1-n} Q\right)^{1 / n}
$$

where $R$ and $Q$ were taken from the values of the corresponding time constants.

Figure 8 shows the variation of $R-C$ parameters from each time constant with respect to HCE concentration and the immersion time, respectively. It should be mentioned that the evolution of the $R$ and $C$ parameters determined in the solution containing $1 \mathrm{~g} \mathrm{~L}^{-1} \mathrm{HCE}$ followed a rather similar behaviour to those obtained in the presence of $0.75 \mathrm{~g} \mathrm{~L}^{-1} \mathrm{HCE}$ and, for the sake of simplicity, they were further neglected from the subsequent discussions. Considering each time constant in turn, the following observations can be derived:

(1) $R_{\mathrm{f}}-C_{\mathrm{f}}$ couple. The addition of $0.1 \mathrm{~g} \mathrm{~L}^{-1} \mathrm{HCE}$ to the test solution originated a gradual increase of the film resistance values from ca. $0.19 \mathrm{k} \Omega \mathrm{cm}^{2}$ to $1.3 \mathrm{k} \Omega \mathrm{cm}^{2}$ during the first 14 -h of exposure (cf. Figure 8A), whereas the film capacitance decreased and attained the lowest value of $1.3 \mu \mathrm{F} \mathrm{cm}^{-2}$ (see Figure $8 \mathrm{~B}$ ). After that period, the values of $R_{\mathrm{f}}$ remained almost constant up to 36-h immersion and $C_{\mathrm{f}}$ increased slightly towards the end of the experiment. These results are consistent with the formation of a thin protective film, likely due to the progressive adsorption of HCE components on the bronze surface, through their available adsorption centres that were identified using FTIR, GC-MS and HPLC measurements. A gradual thickening of the surface film takes place within the first 14-h of exposure, which makes the ionic conduction through this layer more difficult. The increase of HCE concentration to $0.5 \mathrm{~g} \mathrm{~L}^{-1}$ resulted in a significant decrease of $C_{\mathrm{f}}$ values at the initial stages of immersion, while simultaneously the film resistance was about 40 times higher after 1-h of exposure (namely, $R_{\mathrm{f}}=7.6 \mathrm{k} \Omega \mathrm{cm}^{2}$ ) compared to the value of $R_{\mathrm{f}}$ determined in the solution containing $0.1 \mathrm{~g} \mathrm{~L}^{-1} \mathrm{HCE}$.

In the case of $0.5 \mathrm{~g} \mathrm{~L}^{-1} \mathrm{HCE}$, the adsorption of the inhibitor on the bronze surface was facilitated, allowing the formation of a less permeable surface film within 1-h exposure. As time elapsed, the surface film grew slowly and progressively became more compact and resistant towards the passage of the metallic ions through the pores of the film. Nevertheless, the permeability of this surface film towards charged species decreased in some extent after 14-h of exposure, as demonstrated by the small decrease of the $R_{\mathrm{f}}$ values at this stage. A further increase 
of HCE concentration to $0.75 \mathrm{~g} \mathrm{~L}^{-1}$ did not contribute to improve the resistance of the surface film; that is, the corresponding $R_{\mathrm{f}}$ values were lower than those obtained in the presence of $0.5 \mathrm{~g}$ $\mathrm{L}^{-1}$ HCE. Although some film thickening took place on the bronze surface exposed to the solution containing $0.75 \mathrm{~g} \mathrm{~L}^{-1}$ of the inhibitor, its protective characteristics deteriorated at long immersion times.

(2) $R_{\mathrm{ct}}-C_{\mathrm{dl}}$ couple. As shown in Figure $8 \mathrm{C}$, the values of the charge transfer resistance, $R_{\mathrm{ct}}$, increased with $\mathrm{HCE}$ concentration up to $0.5 \mathrm{~g} \mathrm{~L}^{-1}$, and they slightly decreased above this concentration. A progressive augmentation of $R_{\mathrm{ct}}$ values with the immersion time was noticed within the first 14-h of exposure, disregarding the inhibitor concentration. Beyond this time, a decreasing trend of $R_{\mathrm{ct}}$ values could be observed in Figure 8C for all the considered HCE concentrations. However, the decay of $R_{\mathrm{ct}}$ was more pronounced in the presence of $0.75 \mathrm{~g} \mathrm{~L}^{-1}$ HCE. The results proved the ability of HCE to hinder the charge transfer reaction. Its inhibitive properties were initially enhanced for some time, although they started to diminish at a slow pace for long exposures, and more particularly when the HCE concentration exceeded $0.5 \mathrm{~g} \mathrm{~L}^{-1}$.

The double-layer capacitance, $C_{\mathrm{dl}}$ values were lower in the presence of HCE with respect to the uninhibited solution and gradually decreased during about 20-h of exposure; after that period, the values of $C_{\mathrm{dl}}$ remained almost constant until the end of the experiments, except for the solution containing $0.75 \mathrm{~g} \mathrm{~L}^{-1}$ (see Figure 8D). In this later case, the $C_{\mathrm{dl}}$ values increased at long immersion and attained values as high as those corresponding to the uninhibited solution. This decrease of $C_{\mathrm{dl}}$ could be attributed to a smaller exposed area directly in contact with the corrosive solution, on which the charge transfer reaction might occur, and/or to the progressive replacement of the water molecules by the adsorbed organic molecules with low dielectric constant within the double layer [27].

(3) $R_{\mathrm{F}}-C_{\mathrm{F}}$ couple. This couple is mainly attributed to the kinetics of a reversible redox process involving a surface species (i.e. $\mathrm{Cu}_{2} \mathrm{O}$ ) accumulated during the corrosion process, according to a mechanism based on the following sequence of reactions [19]:

$$
\begin{aligned}
& \mathrm{Cu} \rightleftarrows \mathrm{Cu}(\mathrm{I})_{\mathrm{ad}}+\mathrm{e}^{-} \\
& \mathrm{Cu}(\mathrm{I})_{\mathrm{ad}} \rightarrow \mathrm{Cu}(\mathrm{II})+\mathrm{e}^{-}
\end{aligned}
$$

For all the studied HCE concentrations, the faradaic resistance, $R_{\mathrm{F}}$, tended to increase with the immersion time during the first 10-14 h of immersion (cf. Figure 8E), in accordance with the corresponding variation of $C_{\mathrm{dl}}$ values (Figure 8D). As time elapsed, except for the 
solution containing $0.75 \mathrm{~g} \mathrm{~L}^{-1} \mathrm{HCE}, R_{\mathrm{F}}$ attained an almost steady-state condition, with values 7 to 10 times greater than those obtained in the uninhibited solution. Simultaneously, the capacitances associated to this process that were determined in the presence of HCE were lower than the $C_{\mathrm{F}}$ values obtained for the blank solution, as shown in Figure 8F. As expected, the greatest $R_{\mathrm{F}}$ values were obtained in the presence of $0.5 \mathrm{~g} \mathrm{~L}^{-1} \mathrm{HCE}$ at all immersion times, while $C_{\mathrm{F}}$ attained its lowest values at this HCE concentration as well.

The obtained results suggest that the adsorption of HCE stabilizes the corrosion products formed on the surface, which became less susceptible to participate in the redox reaction between $\mathrm{Cu}$ and $\mathrm{Cu}_{2} \mathrm{O}$. However, by increasing the $\mathrm{HCE}$ concentration to $0.75 \mathrm{~g} \mathrm{~L}^{-1}$, the electrochemical (faradaic) processes occurring at the bronze surface might eventually be accelerated at longer exposure times [13], which would give rise to higher $C_{\mathrm{F}}$ values.

It is known [61] that in the presence of redox processes taking place on the metallic surface, the polarization resistance, $R_{\mathrm{p}}$, is better correlated with the corrosion rate than $R_{\mathrm{ct}}$. Since the film resistance, $R_{f}$ is a non-faradic parameter, the polarization resistance $R_{\mathrm{p}}$ could be defined as:

$$
R_{\mathrm{p}}=R_{\mathrm{ct}}+R_{\mathrm{F}}
$$

The $R_{\mathrm{p}}$ values were used to calculate the inhibition efficiency, $z$, according to the following equation:

$$
z(\%)=\frac{R_{\mathrm{p}}-R_{\mathrm{p}}^{0}}{R_{\mathrm{p}}} \cdot 100
$$

where $R_{\mathrm{p} \text { and }} R_{\mathrm{P}}^{0}$ are the polarization resistances in solutions with and without $\mathrm{HCE}$, respectively. Figure 9 shows the time evolution of $R_{\mathrm{p}}$ and $z$ values during the exposure to the corrosive solutions in the absence and in the presence of HCE at different concentrations. The polarization resistance increased with time and presented its highest values in solutions containing $0.5 \mathrm{~g} \mathrm{~L}^{-1} \mathrm{HCE}$. Above this concentration, a decrease of the $R_{\mathrm{p}}$ values could be noticed, particularly at longer immersion, as expected from the above-mentioned results.

After 1-h immersion, the anticorrosive effectiveness of the HCE is rather moderate, as shown in Figure 9B. A gradual reinforcement of its inhibiting properties was noticed after about 14-h when $z(\%)$ attained maximum values of $84.8 \%, 94.1 \%$ and $82.8 \%$ for HCE concentrations of $0.1,0.5$ and $0.75 \mathrm{~g} \mathrm{~L}^{-1}$, respectively. Although the inhibitive efficiencies of HCE decreased 
slightly at longer immersions up to $36-\mathrm{h}$, this natural product offered acceptably lasting anticorrosive protection to bronze in $0.2 \mathrm{~g} \mathrm{~L}^{-1} \mathrm{Na}_{2} \mathrm{SO}_{4}+0.2 \mathrm{~g} \mathrm{~L}^{-1} \mathrm{NaHCO}_{3}$ ( $\mathrm{pH}$ 5) solution.

Although the complex chemical composition of HCE makes rather difficult to assign its inhibiting action to a particular constituent or group of constituents, some preliminary EIS experiments were performed using the two main components identified in the HCE (cf. Tables 1 and 2), namely quercetin and kaempferol. This choice was based on reports of corrosion inhibition effects provided by several plant extracts containing phenolic acids and flavonoids as chemical constituents [62]. Firstly, $12.5 \mathrm{ppm}$ of quercetin were added to the blank test solution, a value close to the overall concentration of quercetin and its derivatives (i.e., $250 \mathrm{ppm}$ ) in $0.5 \mathrm{~g}$ $\mathrm{L}^{-1} \mathrm{HCE}$. It was found that the appearance of the treated bronze surface resembled that developed in the corresponding HCE-containing solution, whereas the measured EIS data (not shown here)followed quite closely the impedance diagram of $0.5 \mathrm{~g} \mathrm{~L}^{-1} \mathrm{HCE}$ although with slightly smaller total impedances. Upon the increase of the quercetin concentration up to $25 \mathrm{ppm}$, the impedance increased closer to that of the HCE-containing solution, but precipitation of the compound from the solution occurred in less than $2 \mathrm{~h}$, even if ethanol was employed for dissolution. This feature effectively prevented us from testing higher concentrations of quercetin. On the other hand, in a similar experiment involving kaempferol, no inhibiting effect could be observed against the corrosion of bronze in simulated acid rain.In summary, compounds of the quercetin group may be considered to contribute to the inhibition corrosion effect for bronze reported in this work, but they may produce such effect together with other substances, and the eventual occurrence of synergistic effects could not be discarded at this stage.

\subsection{SEM-EDS characterization}

Figure 10 shows SEM micrographs and the corresponding EDS spectra of bronze surfaces after $36 \mathrm{~h}$ exposure to $0.2 \mathrm{~g} \mathrm{~L}^{-1} \mathrm{Na}_{2} \mathrm{SO}_{4}+0.2 \mathrm{~g} \mathrm{~L}^{-1} \mathrm{NaHCO}_{3}$ (pH 5) solution in the absence and presence of $0.5 \mathrm{~g} \mathrm{~L}^{-1} \mathrm{HCE}$. It should be noted that the parallel features observable on the bronze surfaces after exposure to the test solutions without and with HCE originated from the prior surface preparation step that originated grinding scratches.

It can be seen in Figure 10A that the bronze surface appeared to be rough and covered with a layer of corrosion products after 36-h exposure to the uninhibited corrosive solution. The EDS analysis in Figure 10C revealed high amounts of oxygen on the bronze surface, in addition 
to the major elements $(\mathrm{Cu}$ and $\mathrm{Sn})$. Hence, the corrosion products would be mainly metal oxyhydroxides.

The morphology of the bronze surface after its immersion in the solution containing $0.5 \mathrm{~g}$ $\mathrm{L}^{-1}$ HCE was significantly different (see Figure 10B). A marked decrease of the surface roughness occurred in the presence of the inhibitor, and it must be regarded to result from $\mathrm{HCE}$ adsorption on the metallic surface. Although some oxides are still present on the bronze surface treated with $0.5 \mathrm{~g} \mathrm{~L}^{-1} \mathrm{HCE}$ as shown in the EDS spectra shown in Figure 10D, a significant decrease of the oxygen peak could be noticed when the bronze was in contact with the HCE, thus confirming the corrosion inhibition effect occurring in the investigated experimental conditions. However, the persistence of oxides on the bronze surface after immersion in the HCE-containing solution is reasonable because the inhibiting efficiency of HCE is smaller than $100 \%$.

\subsection{SECM analysis}

To investigate the reactivity of the metal surface and the tendency of bronze to electron transfer with spatial resolution, a random area of $500 \mu \mathrm{m} \times 500 \mu \mathrm{m}$ was chosen on the bronze substrate and 2-D scans were recorded in the amperometric feedback operation mode in the same location. Ferrocene-methanol was used as redox mediator, and the Pt microelectrode tip was polarized at $+0.50 \mathrm{~V}$ vs. $\mathrm{Ag} / \mathrm{AgCl} / \mathrm{KCl}$ (sat.) for the diffusion-controlled oxidation of this species.

Selected SECM images recorded at different immersion times in the inhibitor-free solution are shown in Figure 11. In them, the faradaic current measured at the tip, $i$, was normalized with respect to the limiting current $i_{\text {lim }}$ recorded before each scan acquisition while the tip was placed in the bulk of the solution. Therefore, the $I=i / i_{\lim }$ values greater than 1 evidenced the appearance of a positive feedback effect related to the surface exhibiting a combination of conductive behaviour with kinetic ability to allow the regeneration of the redox mediator following electron transfer from the substrate. In contrast, regions that delivered normalized current values smaller than 1 reflected predominance of negative feedback behaviour and, therefore, showed less surface reactivity. The surface is clearly heterogeneous, but positive feedback is predominant over a great section of the scanned area (yellow and red coloured), thus reflecting an electrochemically-active surface in the absence of the inhibitor. In addition, from a qualitative inspection of the images, the evolution of the SECM scan acquisition showed a greater number of active sites after longer exposure times, which suggests an increase in the 
conductivity and the reactivity of the surface within the first two hours of immersion. Notorious corrosion phenomena occurred after this time in the aggressive environment, so the experimental series was stopped.

The behaviour observed in Figure 12 for a bronze sample immersed in the test solution containing HCE was different from that already described in the blank electrolyte. In this case, a concentration of $0.5 \mathrm{~g} \mathrm{~L}^{-1}$ was chosen for the in situ SECM experiments based on its higher inhibiting efficiency according to the potentiodynamic polarization and impedance measurements described above. Although the scan shown in Figure 12A, which was recorded after 29 min immersion, shows a mostly active surface similar to that in the inhibitor-free conditions (see Figures 11A and 11B), the positive feedback effect was hardly observed after 42 min (cf. Figure 12B) and even longer immersion times (i.e. Figures 12C-D). Conversely, the imaged areas mostly exhibited the insulating-type behaviour and the negative feedback effect, reflecting the formation of anon-reactive layer that progressively blocked the active sites available for the electron donation needed in the regeneration of the redox mediator. Ultimately, almost the entire surface behaved as an insulator, and purely negative feedback effect was observed after $150 \mathrm{~min}$ (Figure 12D). In this stage, the formation of a sufficiently protective inhibitory surface derived in the effective hindrance of the diffusion of the mediator to the tip as only surface feature influencing the SECM response, hence only topographic information can be extracted from the SECM images.

Quantitative kinetic information on the surface tendency towards electron donation is accessible by recording the tip current while the tip is moved towards the investigated sample surface at some selected location [63]. The resulting probe approach curve (PAC) provides information about constant rate of the heterogeneous electron transfer for the reduction at the metal substrate of the ferrocinium species, which results from the oxidation of the redox mediator at the tip. The 2-D scans in Figures 11 and 12 confirmed that the constant rate changed dynamically and heterogeneously throughout the bronze surface. This dynamic behaviour was studied at the randomly chosen location corresponding to the $(0,0)$ origin of the maps in Figures 11 and 12. The resulting Z-approach curves are shown in Figure 13 for the sequence of PACs recorded at different elapsed times during the immersion of the samples in the inhibitor-free and the HCE-containing solution, respectively. 
In the blank solution containing $0.2 \mathrm{~g} \mathrm{~L}^{-1} \mathrm{Na}_{2} \mathrm{SO}_{4}+0.2 \mathrm{~g} \mathrm{~L}^{-1} \mathrm{NaHCO}_{3}+1 \mathrm{mM}$ ferrocenemethanol ( $\mathrm{pH}$ 5), an almost constant positive feedback behaviour typical of an electrochemically active surface was observed throughout the entire experimental series (see Figure 13A). On the contrary, when the same evolution was investigated in the presence of the HCE, the initial positive feedback diminished with the elapse of time as seen in Figure 13B, which evidences mixed positive-negative feedback behaviour. The limiting purely positive and negative feedback effects are also shown in the figure for the sake of comparison. However, a rather different dynamic evolution trend was recorded when selecting a different location on the bronze surface at which the $Z$-approach curves were recorded. For instance, Figure $13 \mathrm{C}$ shows the results obtained when the approach curves were performed at $100 \mu \mathrm{m}$ far from the origin in the $Y$ direction (a location indicated by a green arrow in Figure 12A), which corresponded to a largely inactive region from the beginning of the experiment. In both cases, the PACs ultimately described purely negative feedback behaviour after 21-h immersion, regardless of the location in the surface.

Using well-established mathematical simulations for the approach curves in SECM experiments, and taking in account the geometry of the tip, the progressive evolution from positive to negative feedback in Figure 13B resulted in the calculation of values for the kinetic constant for the electron transfer at the selected locations on the substrate [63]. In the calculations, a diffusion coefficient of $7.60 \times 10^{-6} \mathrm{~cm}^{2} \mathrm{~s}^{-1}$ was used for the redox mediator [64], and the results are listed in Table 5. It is found that the evolution of the blocking effect of the inhibitory layer can be expressed in terms of hindered electron transfer by ca. $70 \%$, i.e., changing from $7.3 \times 10^{-3}$ to $2.1 \times 10^{-3} \mathrm{~s}^{-1}$. However, given the great surface heterogeneity of the system, these results reflect solely the evolution of single random locations, and they should be considered rather as semi-quantitative information instead of precise quantitative parameters describing the tendency of the whole surface.

The dynamic evolution of the SECM scans observed in Figures 11 and 12 can be correlated with the surface conductivity distribution and related protectiveness of the surface layers. In the absence of the inhibitor, the main phenomena involved in this evolution are the formation and dissolution of semiconductive oxide patinas, which seems to be predominant according to the high oxygen content monitored from the post-mortem EDS evaluation (cf. Figure 10C). As result of the treatment with the HCE inhibitor, the EDS observations did not 
show an extensive formation of copper oxide, so the formation of patinas cannot account for the corrosion protection effect. The protection must stem from the adsorption of HCE on the bronze or the precipitation of metal cations with the complexing species, which occur heterogeneously within the first 1-2 hour immersion according to observations of SECM.

The dynamics of the evolution of the surface conductivity, resulting from the formation of patinas in inhibitor-free solution and for inhibitor-containing layers in the presence of HCE, can be analysed quantitatively from histograms depicting the distribution of the values of normalized current recorded in the scans shown in Figures 11 and 12. Figure 14A shows the histograms obtained for the analysis of the data recorded in inhibitor-free and HCE-containing solutions after 23-29 min immersion, whereas Figure 14B shows the corresponding analysis after 70-min. The average value of the Gaussian distributions with their standard deviations $\sigma$ are plotted against the immersion time in Figure 14C for both electrolyte solutions. The position of the Gaussian peaks did not differ much between the two electrolyte solutions at the beginning of the immersion, although it significantly decayed asymptotically with time only when the HCE was present. In the blank solution, the Gaussian peak position remained rather stable with values greater than unity for the normalized current value, showing a predominant and stable positive feedback behaviour overall. It is also noteworthy that the standard deviation increased with time in the absence of the inhibitor, evidencing a predominantly reactive substrate that exhibited a greater heterogeneity as the exposure time elapsed. Conversely, the standard deviation in the HCE-containing solution did not vary significantly, reflecting a constantly heterogeneous surface deactivation that actually affected the entire exposed surface in a similar manner throughout it. This deactivation may actually result from a convolution of the formation of the oxide patinas and the inhibitor adsorption. However, the remarkably different behaviour observed for bronze immersed in each test electrolyte, in terms of average current and deviations, suggests that the decreasing tendency attained upon exposure to HCE-containing media is more likely supported by the inhibiting effect, rather than the copper oxide development.

The asymptotic trend observed for the mean current decrease in the inhibited bronze system can be correlated with the kinetics of the protective layer formation, as it reflects the general blockage of the surface with the inhibitive film. This blockage effect stems from the overall interaction of the substances present in the extract (Tables 1 and 2), with the metal surface. Each of these components may exhibit different adsorption mechanisms and rates, 
eventually influenced by synergistic effects (positive or negative). This is regarded as a frequent drawback when investigating the inhibitive effect of plant extracts due to the multiple compounds present in the matrix [65]. It must be noticed that the present study aimed to explore and demonstrate the ability of SECM to provide quantitative information on the overall adsorption procedure, addressing the dominant adsorption mechanism of the components in the inhibitive extract. Further investigation would be needed to provide insights on the single molecules or mixtures with major role on the adsorption and inhibitive effect and their adsorption mechanisms. However, concerns arise when considering any eventual separation of components from the extract for their more efficient application as inhibitor, since such strategy may compromise the ease and ecology of the direct use of the extract for corrosion protection, in the event of industrial-scale application.

The surface coverage by the adsorbed species could be expected to obey Langmuir isotherm $[32,35,39,40]$, resulting in the surface coverage $\theta$ evolving with immersion time $t$ according to:

$$
\theta(t)=K^{\prime}\left[1-\exp \left(-k_{\text {obs }} t\right)\right]
$$

where $K^{\prime}$ and $k_{\mathrm{obs}}$ are constants depending on the adsorption and desorption rate constants and the concentration of the inhibitor.

The current models for the theoretical estimation of the normalized current values $I=i / i_{\lim }$, measured at the tip while performing the scans upon feedback behaviour, depict a complex mathematical dependence on several experimental variables, namely the kinetic rate constant of the electron transfer at the surface, the tip-to-substrate distance, the probe geometry and the diffusion coefficient of the redox couple [63]. Among them, the only parameter which depends on the surface properties is the kinetic rate constant $k$, which may be expressed as normalized magnitude $\Lambda$, as follows [66]:

$$
A=\frac{k a}{D}
$$

where $a$ is the radius of the microelectrode and $D$ the diffusion coefficient of the redox mediator. Bard and co-workers proposed a linear correlation between the kinetic rate constant $k$ and surface coverage, obtained using SECM in feedback mode for the investigation of mono- and bilayers deposited on gold surfaces [67]: 


$$
k=\frac{4(1-\theta) D}{\pi R_{\mathrm{d}}}
$$

where $R_{\mathrm{d}}$ relates with the dimensions of the pinholes and pores in the layer. Combining equations (9) to (11), we obtain the following expression:

$$
\Lambda=\frac{4 a}{\pi R_{\mathrm{d}}}-\frac{4 a}{\pi R_{\mathrm{d}}} K^{\prime}+\frac{4 a}{\pi R_{\mathrm{d}}} K^{\prime} \exp \left[-k_{\mathrm{obs}} \cdot t\right]
$$

The values of $\Lambda$ can be obtained by establishing a mathematical correlation from the average $I$ values in the Gaussian fit (Figure 14A and B), providing that the remaining parameters are known. Although some concerns may arise from the probe geometry (namely, for $R g$ greater than 20) as not being optimal for such calculation, systematic errors were not expected to exceed $10 \%$ at small tip-substrate distances. Therefore, considering the experimental parameters, the normalized distance may be considered that providing the minimum limiting current $I=0.774$, average value measured after 1260 min immersion when purely negative feedback is attained. This current is obtained for $L=1.12$, that is, 1.12 times the radius of the microelectrode (around $7 \mu \mathrm{m})$. With all these experimental parameters estimated, the $\Lambda$ values have been calculated and displayed in Figure 14D, along with the exponential tendency. The fitting procedure provides a satisfactory correlation $\left(R^{2}=0.98502\right.$ ) with the following parameters: $k_{\mathrm{obs}}=0.0136 \mathrm{~min}^{-1}$ (or $\left.k_{\mathrm{obs}}=2.27 \times 10^{-4} \mathrm{~s}^{-1}\right)$; and $K^{\prime}=0.853$. These values allow the estimation of the adsorption and desorption rate constants [68-70]:

$$
\begin{aligned}
& k_{\text {Qbs }}=k_{\mathrm{a}} C_{\mathrm{HCE}}+k_{\mathrm{d}} \\
& K^{\prime}=\frac{C_{\mathrm{HCE}}}{C_{\mathrm{HCE}}+\frac{k_{\mathrm{a}}}{k_{\mathrm{d}}}}
\end{aligned}
$$

where $C_{\mathrm{HCE}}$ is the concentration of the adsorbed species. In order to provide appropriate thermodynamic data, an average molecular weight must be estimated taking into account the relative abundance of the compounds identified in Tables 1-2. For the current calculations, a value of $263.1 \mathrm{~g} \mathrm{~mol}^{-1}$ was adopted. Hence, $C_{\mathrm{HCE}}$ is taken as $1.90 \times 10^{-3} \mathrm{~mol} \mathrm{~L}^{-1}$, although it is very unlikely that all the organic compounds in the mixture would promote inhibitive effect. By solving this system of equations, the following apparent kinetic rate constants were obtained as results: $k_{\mathrm{a}}=0.102 \mathrm{~s}^{-1} \mathrm{~mol}^{-1} \mathrm{~L}, k_{\mathrm{d}}=3.33 \times 10^{-5} \mathrm{~s}^{-1}$. Adsorption rate constant is significantly greater than other values reported with corrosion inhibitors used for copper as obtained with kinetic studies done with electrochemical quartz microbalance, whereas desorption occurs at much 
slower pace $[69,70]$. The equilibrium constant and resulting free energy for the adsorptiondesorption process are given by:

$$
\begin{aligned}
& K_{\text {eq }}=\frac{k_{\mathrm{a}}}{k_{\mathrm{d}}} \\
& \Delta G=-R T \ln \left(K_{\text {eq }}\right)
\end{aligned}
$$

In this way, $K_{\mathrm{eq}}=3.06 \cdot 10^{3} \mathrm{~mol}^{-1} \mathrm{~L}$, and $\Delta G=-19.9 \mathrm{~kJ} \mathrm{~mol}^{-1}$ apparent values were obtained, in very good agreement with results estimated from EIS measurements after 1 hour exposure. These results account nearly half those encountered for not eco-friendly inhibitors adsorbed on bronze, typically between -30 and $-40 \mathrm{~kJ} \mathrm{~mol}^{-1}$ [71-73]. Hence, promising values supporting physisorption processes were obtained, as expected for the interaction of bronze with organic molecules with oxygen as only heteroatom. Although a complete kinetic model accurately considering all the experimental conditions and current-influential features, including surface coverage, is still needed, the achieved results are acceptable under the expected values, and they demonstrate the efficiency of the chestnut extract as a good and fast inhibitive substance for the protection of bronze, with great tendency towards the adsorption of the inhibiting surface films in contrast to their desorption. To the best of our knowledge, this is the first time that thermodynamic and kinetic parameters were obtained from the analysis and evaluation of SECM experimental data for metal-inhibitor systems governed by an adsorption-desorption process.

\section{Conclusions}

In the present work, the inhibitive behaviour of the ethanolic extract of horse chestnut seeds (Aesculushippocastanum L.)on bronze in a weakly acidic aqueous environment simulating an acidic rain $\left(0.2 \mathrm{~g} \mathrm{~L}^{-1} \mathrm{Na}_{2} \mathrm{SO}_{4}+0.2 \mathrm{~g} \mathrm{~L}^{-1} \mathrm{NaHCO}_{3}, \mathrm{pH}\right.$ 5)was evaluated using a multiscale electrochemical approach. From the obtained results, the following conclusions can be summarized:

1. Horse chestnut extract was able to hinder to some extent the corrosion process of bronze, acting as a mixed-type inhibitor. The anticorrosive effectiveness of HCE was found to increase with its concentration up to an 'optimum' value of $0.5 \mathrm{~g} \mathrm{~L}^{-1}$, and it improved with longer treatment times. The maximum inhibiting efficiencies reached ca. $85 \%$ and $94 \%$ in the presence of $0.5 \mathrm{~g} \mathrm{~L}^{-1} \mathrm{HCE}$, after 1-h and 14-h exposure, respectively. A further increase of the immersion time up to $36-\mathrm{h}$ did not improve the protective properties of HCE. Although the 
inhibition ability of HCE is not the highest desirable, the seeds of horse chestnut are readily available, in large scale and could be valorised as an inexpensive option for resource recovery.

2. EIS measurements showed that the inhibiting effect of HCE is mainly due to the formation of a thin protective film via the adsorption of its components on the bronze surface, which hindered to some extent the charge transfer process and stabilised the corrosion products, offering an improved protection.

3. Potentiodynamic polarisation measurements performed at different temperatures showed that the inhibition ability of HCE decreased slightly at higher temperatures. The thermodynamic parameters indicate that the adsorption mechanism of HCE on bronze surface is of physical nature.

4. SEM-EDS analysis indicated that the bronze dissolution process was mitigated in the presence of the inhibitor, and it produced a smoother bronze surface.

5. The reactivity of the bronze surface and the evolution of its susceptibility to undergo electron transfer reactions was investigated using the SECM in feedback operation, both in the absence and the presence of the inhibitor in the 'optimized' concentration. The analysis of the faradaic current measured at the tip allowed the rate constant for electron transfer between the metal surface and ferrocene-methanol as redox mediator to be determined. This process, dynamically and heterogeneously distributed throughout the substrate surface, allowed available active sites for electron transfer to be imaged in situ during their deactivation upon interaction with the components of the extract with corrosion inhibition characteristics.

6. A novel and promising method for SECM data evaluation on corrosion inhibitor adsorption is proposed. The distribution of the estimated values of the electron transfer rate constant from SECM maps was successfully fitted into Langmuir isotherm, by direct correlation with the surface coverage and blockage of the available sites for the electron donation. Results provided acceptable values for the rate and the equilibrium constants of the overall adsorptiondesorption processes involving the substances present in the extract, supporting that a physisorption mechanism is the main responsible phenomena for the anticorrosive properties.

7. The microelectrochemical characterization of the inhibition characteristics of HCE for the corrosion protection of bronze correlated well with the data obtained using conventional electrochemical techniques. The applied methodology is regarded as particularly promising for 
the investigation of the microscopically heterogeneous adsorption characteristics of green corrosion inhibitors on metals.

8. The inhibition effect of HCE might be related to one specific molecule or to a synergistic effect of the entire extract. Although, HPLC-PDA, GC-MS and FTIR analysis identified the most abundant compounds from HCE, but it was difficult to assign the inhibiting action to a particular constituent or group of constituents. Therefore, further studies are needed to completely understand the involved protection mechanism. This drawback is rather common when investigating corrosion inhibitors derived from plant extracts because they appear as complex mixtures of multiple constituents belonging to different functional groups.

\section{Acknowledgements}

The authors thank Dr. Florin Popa from the Materials Science and Engineering Department, Technical University of Cluj-Napoca (Romania) for assistance in the SEM-EDS characterizations. The work was partially financed by the Spanish Ministry of Economy and Competitiveness (MINECO, Madrid) and the European Regional Development Fund, under grant CTQ2016-80522-P.

One of the authors (S. Varvara) gratefully acknowledge the support offered by Erasmus + Staff Mobility for Training Programme (2018).

\section{Data availability}

The raw/processed data required to reproduce these findings cannot be shared at this time due to technical or time limitations.

\section{References}

[1] Z. Wang, Y. Li, X. Jiang, C. Pan, Research Progress on Ancient Bronze Corrosion in Different Environments and Using Different Conservation Techniques: A Review, MRS Adv. 2 (2017) 2033-2041. doi:10.1557/adv.2017.222.

[2] F.J.R. de Oliveira, D.C.B. Lago, L.F. Senna, L.R.M. de Miranda, E. D’Elia, Study of patina formation on bronze specimens, Mater. Chem. Phys. 115 (2009) 761-770. doi:10.1016/j.matchemphys.2009.02.035. 
[3] T. Kosec, H.O. Curković, A. Legat, Investigation of the corrosion protection of chemically and electrochemically formed patinas on recent bronze, Electrochim. Acta. 56 (2010) 722-731. doi:10.1016/j.electacta.2010.09.093.

[4] G. Di Carlo, C. Giuliani, C. Riccucci, M. Pascucci, E. Messina, G. Fierro, M. Lavorgna, G.M. Ingo, Artificial patina formation onto copper-based alloys: Chloride and sulphate induced corrosion processes, Appl. Surf. Sci. 421 (2017) 120-127. doi:10.1016/j.apsusc.2017.01.080.

[5] B. Rosales, R. Vera, G. Moriena, Evaluation of the protective properties of natural and artificial patinas on copper. Part I. Patinas formed by immersion, Corros. Sci. 41 (1999) 625-651. doi:10.1016/S0010-938X(98)00108-5.

[6] R.D.P.B. Hernández, I. V. Aoki, B. Tribollet, H.G. De Melo, Electrochemical impedance spectroscopy investigation of the electrochemical behaviour of copper coated with artificial patina layers and submitted to wet and dry cycles, Electrochim. Acta. 56 (2011) 2801-2814. doi:10.1016/j.electacta.2010.12.059.

[7] W.A. Badawy, R.M. El-Sherif, H. Shehata, Electrochemical behavior of aluminum bronze in sulfate-chloride media, J. Appl. Electrochem. 37 (2007) 1099-1106. doi:10.1007/s10800-007-9362-9.

[8] C. Chiavari, E. Bernardi, C. Martini, F. Passarini, F. Ospitali, L. Robbiola, The atmospheric corrosion of quaternary bronzes: The action of stagnant rain water, Corros. Sci. 52 (2010) 3002-3010. doi:10.1016/j.corsci.2010.05.013.

[9] S. Aouadi, N. Souissi, Early stages of tin bronze corrosion in neutral aqueous chloride media: Electrochemical and FTIR investigations, Mater. Corros. 67 (2016) 1105-1113. doi:10.1002/maco.201608856.

[10] X. Liao, F. Cao, J. Zhang, Effect of sulphate on the corrosion behavior of bronze under a chloride-containing thin electrolyte layer, Mater. Corros. 69 (2018) 1412-1421. doi: $10.1002 / \operatorname{maco} .201810132$.

[11] L. Muresan, S. Varvara, E. Stupnišek-Lisac, H. Otmačić, K. Marušić, S. HorvatKurbegović, L. Robbiola, K. Rahmouni, H. Takenouti, Protection of bronze covered with patina by innoxious organic substances, Electrochim. Acta. 52 (2007) 7770-7779. doi:10.1016/j.electacta.2007.02.024.

[12] S. Varvara, R. Bostan, L. Gəinə, L.M. Muresan, Thiadiazole derivatives as inhibitors for 
acidic media corrosion of artificially patinated bronze, Mater. Corros. 65 (2014) 12021214. doi:10.1002/maco.201307072.

[13] W. Qafsaoui, A.E. Taouil, M.W. Kendig, H. Cachet, S. Joiret, H. Perrot, H. Takenouti, Coupling of electrochemical, electrogravimetric and surface analysis techniques to study dithiocarbamate/bronze interactions in chloride media, Corros. Sci. 130 (2018) 190-202. doi:10.1016/j.corsci.2017.10.034.

[14] M.M. Antonijevic, M.B. Petrovic Mihajlovic, Copper corrosion inhibitors. A review, Int. J. Electrochem. Sci. 3 (2008) 1-28. doi:10.1016/j.ijengsci.2004.12.001.

[15] M.M. Antonijevic, M.B. Petrovic Mihajlovic, Copper Corrosion Inhibitors. Period 20082014. A Review, Int. J. Electrochem. Sci. 10 (2015) 1027-1053. doi:10.1016/j.ijengsci.2004.12.001.

[16] Ž.Z. Tasić, M.B. Petrović Mihajlović, M.B. Radovanović, M.M. Antonijević, New trends in corrosion protection of copper, Chem. Pap. 73 (2019) 2103-2132. doi:10.1007/s11696019-00774-1.

[17] G. Laguzzi, L. Luvidi, Evaluation of the anticorrosive properties of benzotriazole alkyl derivatives on 6\% Sn bronze alloy, Surf. Coatings Technol. 204 (2010) 2442-2446. doi:10.1016/j.surfcoat.2010.01.019.

[18] M. Finšgar, I. Milošev, Inhibition of copper corrosion by 1,2,3-benzotriazole: A review, Corros. Sci. 52 (2010) 2737-2749. doi:10.1016/j.corsci.2010.05.002.

[19] K. Marušić, H.O. Ćurković, H. Takenouti, Inhibiting effect of 4-methyl-1-ptolylimidazole to the corrosion of bronze patinated in sulphate medium, Electrochim. Acta. 56 (2011) 7491-7502. doi:10.1016/j.electacta.2011.06.107.

[20] I. Milošev, N. Kovačević, J. Kovač, A. Kokalj, The roles of mercapto, benzene and methyl groups in the corrosion inhibition of imidazoles on copper: I. Experimental characterization, Corros. Sci. 98 (2015) 107-118. doi:10.1016/j.corsci.2015.05.006.

[21] M.B. Petrović Mihajlović, M.B. Radovanović, Ž.Z. Tasić, M.M. Antonijević, Imidazole based compounds as copper corrosion inhibitors in seawater, J. Mol. Liq. 225 (2017) 127136. doi:10.1016/j.molliq.2016.11.038.

[22] A. Dermaj, N. Hajjaji, S. Joiret, K. Rahmouni, A. Srhiri, H. Takenouti, V. Vivier, Electrochemical and spectroscopic evidences of corrosion inhibition of bronze by a triazole derivative, Electrochim. Acta. 52 (2007) 4654-4662. 
doi:10.1016/j.electacta.2007.01.068.

[23] M.M. Antonijević, S.M. Milić, M.B. Petrović, Films formed on copper surface in chloride media in the presence of azoles, Corros. Sci. 51 (2009) 1228-1237. doi:10.1016/j.corsci.2009.03.026.

[24] S. Varvara, L.M. Muresan, K. Rahmouni, H. Takenouti, Evaluation of some non-toxic thiadiazole derivatives as bronze corrosion inhibitors in aqueous solution, Corros. Sci. 50 (2008) 2596-2604. doi:10.1016/j.corsci.2008.06.046.

[25] D.C.B. Do Lago, L.F. De Senna, E.C.S. Soares, L.F. da Silva, D.S. Fernandes, A.S. Luna, E. D'Elia, The use of experimental design for the study of the corrosion of bronze pretreated with AMT in artificial rainwater, Prog. Org. Coatings. 76 (2013) 1289-1295. doi:10.1016/j.porgcoat.2013.03.032.

[26] H. Tian, W. Li, K. Cao, B. Hou, Potent inhibition of copper corrosion in neutral chloride media by novel non-toxic thiadiazole derivatives, Corros. Sci. 73 (2013) 281-291. doi:10.1016/j.corsci.2013.04.017.

[27] C. Monticelli, A. Balbo, J. Esvan, C. Chiavari, C. Martini, F. Zanotto, L. Marvelli, L. Robbiola, Evaluation of 2-(salicylideneimino) thiophenol and other Schiff bases as bronze corrosion inhibitors by electrochemical techniques and surface analysis, Corros. Sci. 148 (2019) 144-158. doi:10.1016/j.corsci.2018.12.017.

[28] S. Varvara, M. Popa, L.M. Muresan, Corrosion inhibition of bronze by amino acids in aqueous acidic solutions, Stud. Univ. Babes-Bolyai Chem. 3 (2009) 235-247.

[29] T. Wang, J. Wang, Y. Wu, The inhibition effect and mechanism of l-cysteine on the corrosion of bronze covered with a $\mathrm{CuCl}$ patina, Corros. Sci. 97 (2015) 89-99. doi:10.1016/j.corsci.2015.04.018.

[30] L.T. Popoola, Organic green corrosion inhibitors (OGCIs): A critical review, Corros. Rev. 37 (2019) 71-102. doi:10.1515/corrrev-2018-0058.

[31] B.A. Abd-El-Nabey, A.H. Abdel-Gaber, M.E.S. Ali, E. Khamis, S. El-Housseiny, Inhibitive Action of cannabis plant extract on the corrosion of copper in $0.5 \mathrm{M} \mathrm{H}_{2} \mathrm{SO}_{4}$, Int. J. Electrochem. Sci. 8 (2013) 7124-7137.

[32] K. Krishnaveni, J. Ravichandran, Influence of aqueous extract of leaves of Morinda tinctoria on copper corrosion in $\mathrm{HCl}$ medium, J. Electroanal. Chem. 735 (2014) 24-31. doi:10.1016/j.jelechem.2014.09.032. 
[33] M.A. Deyab, Egyptian licorice extract as a green corrosion inhibitor for copper in hydrochloric acid solution, J. Ind. Eng. Chem. 22 (2015) 384-389. doi:10.1016/j.jiec.2014.07.036.

[34] A.S. Fouda, M.A. Elmorsi, B.S. Abou-Elmagd, Adsorption and inhibitive properties of methanol extract of Eeuphorbia Heterophylla for the corrosion of copper in $0.5 \mathrm{M}$ nitric acid solutions, Polish J. Chem. Technol. 19 (2017) 95-103. doi:10.1515/pjct-2017-0014.

[35] F. Wedian, M.A. Al-Qudah, G.M. Al-Mazaideh, Corrosion inhibition of copper by Capparis spinosa L. extract in strong acidic medium: Experimental and density functional theory, Int. J. Electrochem. Sci. 12 (2017) 4664-4676. doi:10.20964/2017.06.47.

[36] A. Jmiai, B. El Ibrahimi, A. Tara, M. Chadili, S. El Issami, O. Jbara, A. Khallaayoun, L. Bazzi, Application of Zizyphus Lotuse - pulp of Jujube extract as green and promising corrosion inhibitor for copper in acidic medium, J. Mol. Liq. 268 (2018) 102-113. doi:10.1016/j.molliq.2018.06.091.

[37] H. Gerengi, K. Schaefer, H.I. Sahin, Corrosion-inhibiting effect of Mimosa extract on brass-MM55 corrosion in 0.5 M H 2SO 4 acidic media, J. Ind. Eng. Chem. 18 (2012) 2204-2210. doi:10.1016/j.jiec.2012.06.019.

[38] T. Ramde, S. Rossi, C. Zanella, Inhibition of the Cu65/Zn35 brass corrosion by natural extract of Camellia sinensis, Appl. Surf. Sci. 307 (2014) 209-216. doi:10.1016/j.apsusc.2014.04.016.

[39] A.S. Fouda, K. Shalabi, A.A. Idress, Ceratonia siliqua extract as a green corrosion inhibitor for copper and brass in nitric acid solutions, Green Chem. Lett. Rev. 8 (2015) 17-29. doi:10.1080/17518253.2015.1073797.

[40] H.S. Gadow, M.M. Motawea, H.M. Elabbasy, Investigation of myrrh extract as a new corrosion inhibitor for $\alpha$-brass in $3.5 \% \mathrm{NaCl}$ solution polluted by $16 \mathrm{ppm}$ sulfide, RSC Adv. 7 (2017) 29883-29898. doi:10.1039/c7ra04271j.

[41] B. Benzidia, H. Hammouch, A. Dermaj, H. Benassaoui, S. Abbout, N. Hajjaji, Investigation of green corrosion inhibitor based on aloe vera (L.) burm. F. for the protection of bronze B66 in 3\% NaCl, Anal. Bioanal. Electrochem. 11 (2019) 165-177.

[42] R. Ben Channouf, N. Souissi, N. Bellakhal, Juniperus communis extract effect on bronze corrosion in natural 0.5 M chloride medium, J. Mater. Sci. Chem. Eng. 3 (2015) 21-29. doi:10.4236/msce.2015.311004. 
[43] A.K. Larios-Galvez, J. Porcayo-Calderon, V.M. Salinas-Bravo, J.G. Chacon-Nava, J.G. Gonzalez-Rodriguez, L. Martinez-Gomez, Use of Salvia hispanica as an eco-friendly corrosion inhibitor for bronze in acid rain, Anti-Corrosion Methods Mater. 64 (2017) 654663. doi:10.1108/ACMM-02-2017-1760.

[44] S. Varvara, R. Bostan, O. Bobis, L. Găină, F. Popa, V. Mena, R.M. Souto, Propolis as a green corrosion inhibitor for bronze in weakly acidic solution, Appl. Surf. Sci. 426 (2017) 1100-1112. doi:10.1016/j.apsusc.2017.07.230.

[45] V. Pourzarghan, H. Sarhaddi-Dadian, H. Bakhshandefard, Feasibility study of natural honey use as corrosion inhibitor in protecting the bronze artifacts, Mediterr. Archaeol. Archaeom. 17 (2017) 301-309. doi:10.5281/zenodo.1048935.

[46] G. Foca, A. Ulrici, M. Cocchi, C. Durante, M. Li Vigni, A. Marchetti, S. Sighinolfi, L. Tassi, Chapter 76 - Seeds of horse chestnut (Aesculus Hippocastanum L.) and their possible utilization for human consumption, in: V. Preedy, R. Watson, V. Patel (Eds.), Nuts and Seeds in Health and Disease Prevention, Academic Press, Cambridge, MA, 2011, pp. 653-661, https://doi.org/10.1016/B978-0-12-375688-6.10076-3.

[47] L. Muresan, S. Varvara, G. Maurin, S. Dorneanu, Effect of some organic additives upon copper electrowinning from sulphate electrolytes, Hydrometallurgy. 54 (2000) 161-169. doi:10.1016/S0304-386X(99)00063-8.

[48] L. Muresan, L. Oniciu, M. Froment, G. Maurin, Inhibition of lead electrocrystallization by organic additives, Electrochim. Acta. 37 (1992) 2249-2254. doi:10.1016/00134686(92)85119-6.

[49] V.V. Parshutin, N.S. Sholtoyan, S.P. Sidel'nikova, A.V. Koval', I.I. Bulkhak, O.A. Bologa, V.N. Shofranskii, The influence of a water extract of horse chestnut fruit on the corrosion of St3 steel in water, Surf. Eng. Appl. Electrochem. 47 (2011) 276-283. doi:10.3103/S1068375511030161.

[50] R.F. Fan, D. Demaille, Preparation of tips for scanning electrochemical microscopy, in: A.J. Bard, M.V. Mirkin (Eds.), Scanning Electrochem. Microscopy, 2nd ed., CRC Press, Boca Raton, 2012, pp. 25-51.

[51] L. Guadagnini, C. Chiavari, C. Martini, E. Bernardi, L. Morselli, D. Tonelli, The use of scanning electrochemical microscopy for the characterisation of patinas on copper alloys, Electrochim. Acta. 56 (2011) 6598-6606. doi:10.1016/j.electacta.2011.04.080. 
[52] V.L. Singleton, R. Orthofer, R.M. Lamuela-Raventos, Analysis of total phenols and other oxidation substrates and antioxidants by means of Folin-Ciocalteu reagent, Methods Enzymol. 299 (1999) 152-178.

[53] A. Arvouet-Grand, B. Vennat, A. Pourrat, P. Legret, Standardisation d'un extrait de propolis et identification des principaux contituants, J. Pharm. Belg. 4 (1994) 462-468

[54] I. Kapusta, B. Janda, B. Szajwaj, A. Stochmal, S. Piacente, C. Pizza, F. Franceschi, C. Franz, W. Oleszek, Flavonoids in horse chestnut (Aesculus hippocastanum) seeds and powdered waste water byproducts, J Agric. Food Chem. 55(2007) 8485-8490. doi:10.1021/jf071709t.

[55] V.A.Kurkin, P.V. Belov, V.M. Ryzhov, Quantitative determination of total flavonoids in horse chestnut Aesculus hippocastanuim buds, Pharm. Chem. J. 53(2019) 155-159. doi:10.1007/s1 1094-019-01970-9

[56] F. Bentiss, M. Lebrini, M. Lagrenée, Thermodynamic characterization of metal dissolution and inhibitor adsorption processes in mild steel/2,5-bis(n-thienyl)-1,3,4thiadiazoles/ hydrochloric acid system, Corros. Sci. 47 (2005) 2915-2931. doi:10.1016/j.corsci.2005.05.034.

[57] A. Popova, M. Christov, A. Vasilev, Mono- and dicationic benzothiazolic quaternary ammonium bromides as mild steel corrosion inhibitors: Part III: Influence of the temperature on the inhibition process, Corros. Sci. 94 (2015) 70-78. doi:10.1016/j.corsci.2015.01.039.

[58] I.D. Raistrick, J.R. MacDonald, D.R. Franceschetti, The electrical analogs of physical and chemical processes, in: J.R. MacDonald (Ed.), Impedance Spectrosc. Emphasizing Solid Mater. Syst., John Wiley \& Sons, New York, NY, 1987: pp. 27-84.

[59] K. Rahmouni, N. Hajjaji, M. Keddam, A. Srhiri, H. Takenouti, The inhibiting effect of 3methyl 1,2,4-triazole 5-thione on corrosion of copper in $3 \% \mathrm{NaCl}$ in presence of sulphide, Electrochim. Acta. 52 (2007) 7519-7528. doi:10.1016/j.electacta.2006.12.079.

[60] G.J. Brug, A.L.G. van der Eeden, M. Sluyters-Rehbach, J.H. Sluyters, The analysis of electrode impedances complicated by the presence of a constant phase element, J. Electroanal. Chem. 176 (1984) 275-295. doi:10.1016/S0022-0728(84)80324-1.

[61] I. Epelboin, C. Gabrielli, M. Keddam, H. Takenouti, A-C impedance measurements applied to corrosion studies and corrosion rate determination, in: F. Mansfeld, U. Bertocci 
(Eds.), Electrochem. Corros. Testing, STP 727, American Society for Testing and Materials, Philadelphia, PA, 1981: pp. 150-192.

[62] E.E. Oguzie, Evaluation of the inhibitive effect of some plant extracts on the acid corrosion of mild steel, Corros. Sci. 50(2008) 2993-2998. doi:10.1016/j.corsci.08.08.004

[63] C. Lefrou, R. Cornut, Analytical expressions for quantitative scanning electrochemical microscopy (SECM), ChemPhysChem. 11 (2010) 547-556. doi:10.1002/cphc.200900600.

[64] Y. Yu, Y. Gao, K. Hu, P.Y. Blanchard, J.M. Noël, T. Nareshkumar, K.L. Phani, G. Friedman, Y. Gogotsi, M. V. Mirkin, Electrochemistry and electrocatalysis at single gold nanoparticles attached to carbon nanoelectrodes, ChemElectroChem. 2 (2015) 58-63. doi:10.1002/celc.201402312.

[65] S. Marzorati, L. Verotta, S.P. Trasatti, Green corrosion inhibitors from natural sources and biomass wastes, Molecules 24 (2019) 48-71. doi:10.3390/molecules24010048.

[66] R. Cornut, C. Lefrou, New analytical approximation of feedback approach curves with a microdisk SECM tip and irreversible kinetic reaction at the substrate, J. Electroanal. Chem. 621 (2008) 178-184. doi:10.1016/j.jelechem.2007.09.021.

[67] C. Cannes, F. Kanoufi, A.J. Bard, Cyclic voltammetry and scanning electrochemical microscopy of ferrocenemethanol at monolayer and bilayer-modified gold electrodes, $\mathrm{J}$. Electroanal. Chem. 547 (2003) 83-91. doi:10.1016/S0022-0728(03)00192-X.

[68] D.S. Karpovich, G.J. Blanchard, Direct measurement of the adsorption kinetics of alkanethiolate self-assembled monolayers on a microcrystalline gold surface, Langmuir. 10 (1994) 3315-3322. doi:10.1021/la00021a066.

[69] J.A. Ramírez-Cano, L. Veleva, Direct measurement of the adsorption kinetics of 2mercaptobenzothiazole on a microcrystalline copper surface, Rev. Metal. 52 (2016) e064. doi:10.3989/revmetalm.064.

[70] J.A. Ramírez-Cano, L. Veleva, R.M. Souto, B.M. Fernández-Pérez, Investigating metalinhibitor interaction with EQCM and SVET: 3-amino-1,2,4-triazole on $\mathrm{Au}, \mathrm{Cu}$ and $\mathrm{Au}-\mathrm{Cu}$ galvanic coupling, Mater. Corros. 69 (2018) 115-124. doi:10.1002/maco.201709564.

[71] A.Y. Musa, A.A. Khadom, A.A.H. Kadhum, M.S. Takriff, A.B. Mohamad, The role of 4amino-5-phenyl-4H-1,2,4-triazole-3-thiol in the inhibition of nickel-aluminum bronze alloy corrosion: Electrochemical and DFT studies, Res. Chem. Intermed. 38 (2012) 91103. doi:10.1007/s11164-011-0328-5. 
1041

1042

1043

1044

1045

1046

1047

1048

[72] J.C. D'Ars De Figueiredo, V.F.C. De Lins, V.M. De Bellis, Inhibiting effect of dithiocarbamate on TM 23 bronze alloy corrosion in acid medium, Corros. Eng. Sci. Technol. 48 (2013) 288-293. doi:10.1179/1743278212Y.0000000075.

[73] D.E. Millan-Ocampo, J.A. Hernandez-Perez, J. Porcayo-Calderon, J.P.F. De los Ríos, L.L. Landeros-Martínez, V.M. Salinas-Bravo, J.G. Gonzalez-Rodriguez, L. Martinez, Experimental and theoretical study of Ketoconazole as corrosion inhibitor for bronze in $\mathrm{NaCl}+\mathrm{Na}_{2} \mathrm{SO}_{4}$ solution, Int. J. Electrochem. Sci. 12 (2017) 11428-11445. doi:10.20964/2017.12.22. 


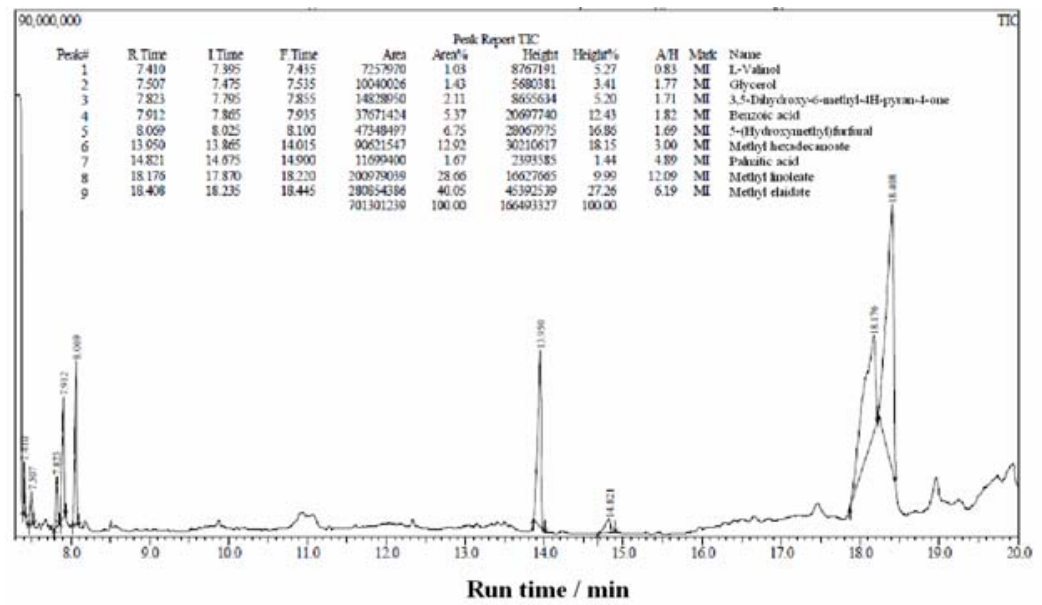

A

1049

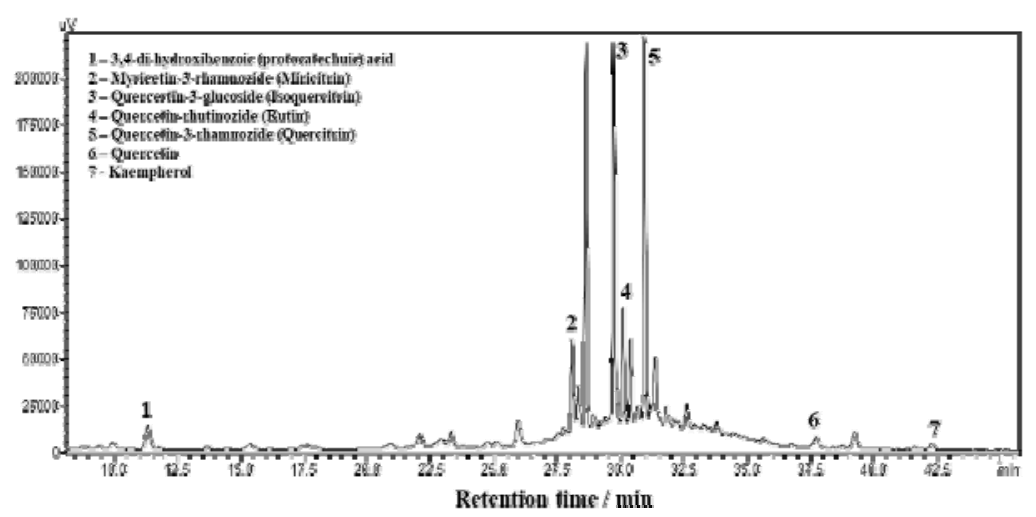

B

Figure 1. Characterization of the ethanolic extract of horse chestnut fruit by: (A) GC-MS and 1052 (B) HPLC-PDA chromatography. 


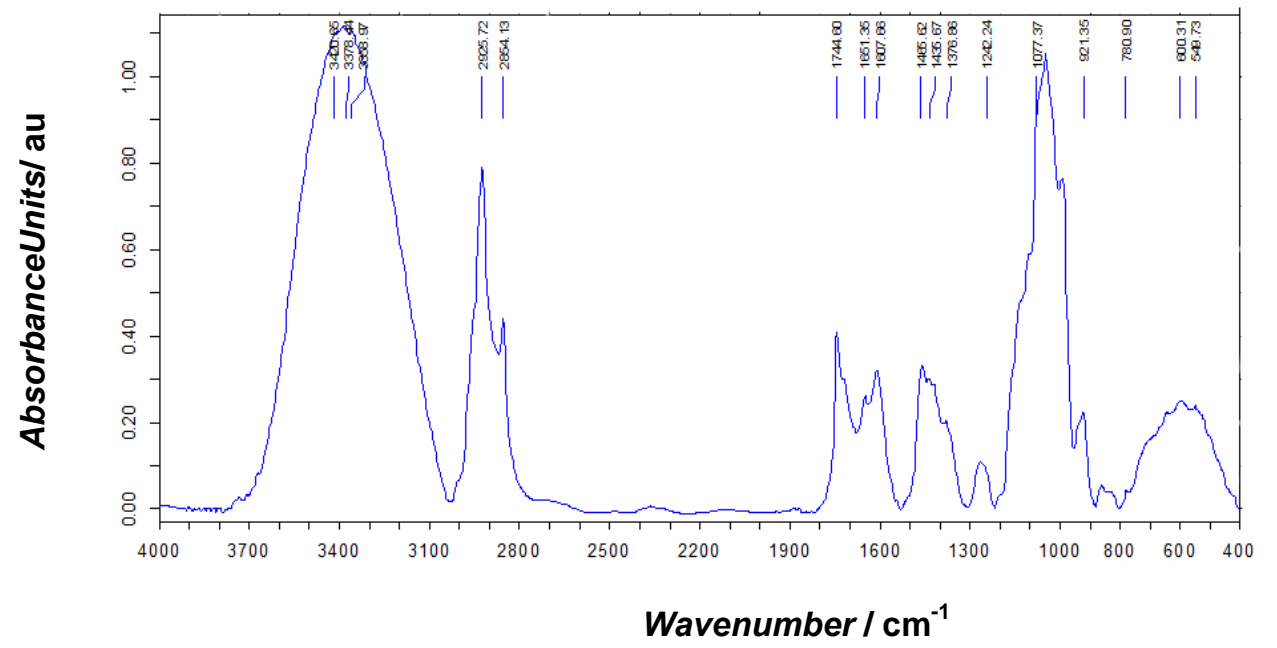

1055

Figure 2. FTIR absorption spectrum of the horse chestnut extract.

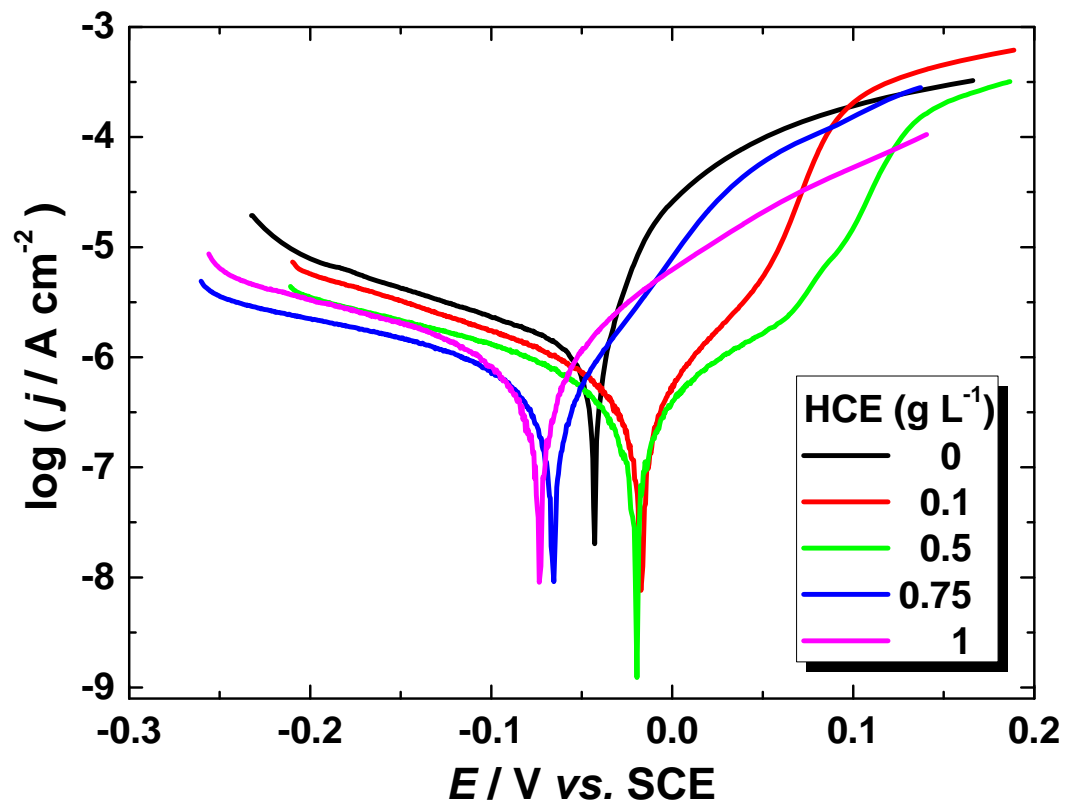

Figure 3. Potentiodynamic polarization curves recorded for bronze samples immersed in $0.2 \mathrm{~g}$ 1060 $\mathrm{L}^{-1} \mathrm{Na}_{2} \mathrm{SO}_{4}+0.2 \mathrm{~g} \mathrm{~L}^{-1} \mathrm{NaHCO}_{3}+x \mathrm{~g} \mathrm{~L}^{-1} \mathrm{HCE}(\mathrm{pH}$ 5) solution at $298 \mathrm{~K}$. 

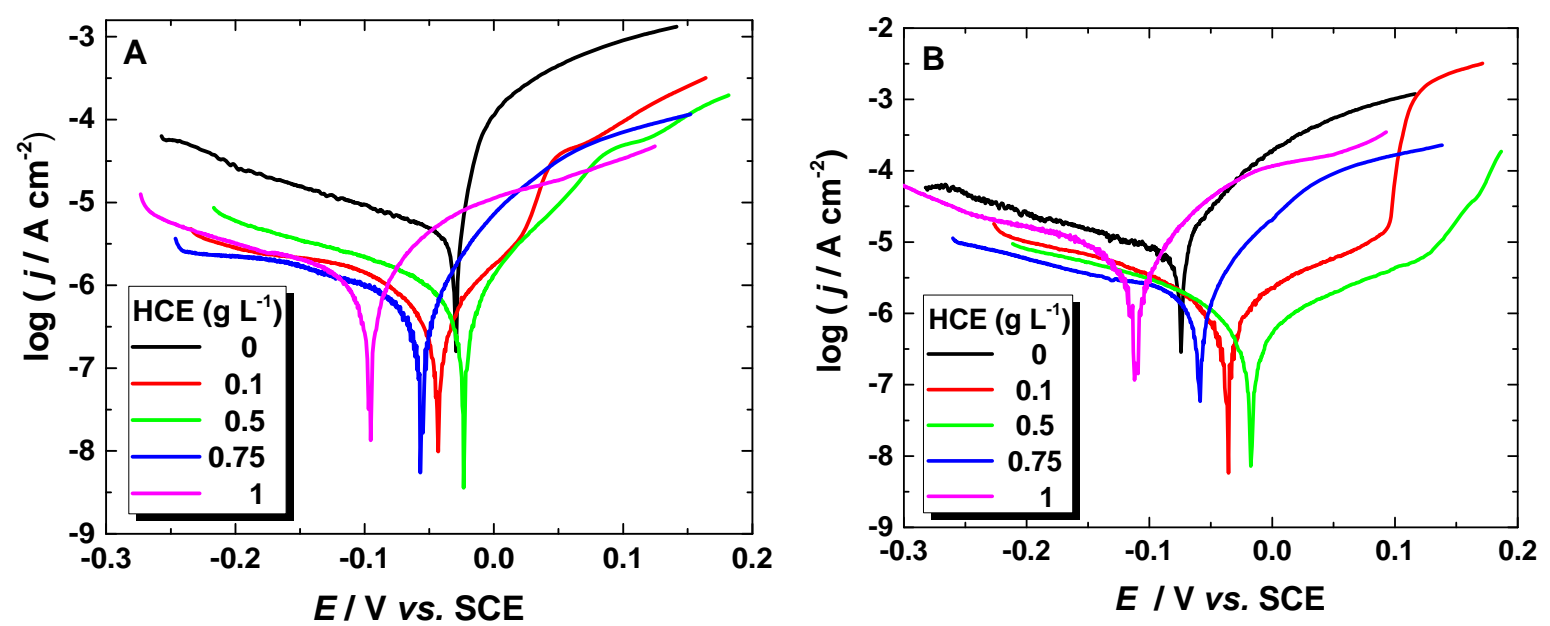

1062

1063

1064

1065

1066

1067

1068

1069

1070

1071

1072

Figure 4. Potentiodynamic polarization curves recorded for bronze electrodes immersed in $0.2 \mathrm{~g}$ $\mathrm{L}^{-1} \mathrm{Na}_{2} \mathrm{SO}_{4}+0.2 \mathrm{~g} \mathrm{~L}^{-1} \mathrm{NaHCO}_{3}+x \mathrm{~g} \mathrm{~L}^{-1} \mathrm{HCE}$ ( $\mathrm{pH}$ 5) solution at various temperatures: (A) 308 $\mathrm{K}$ and (B) $328 \mathrm{~K}$.
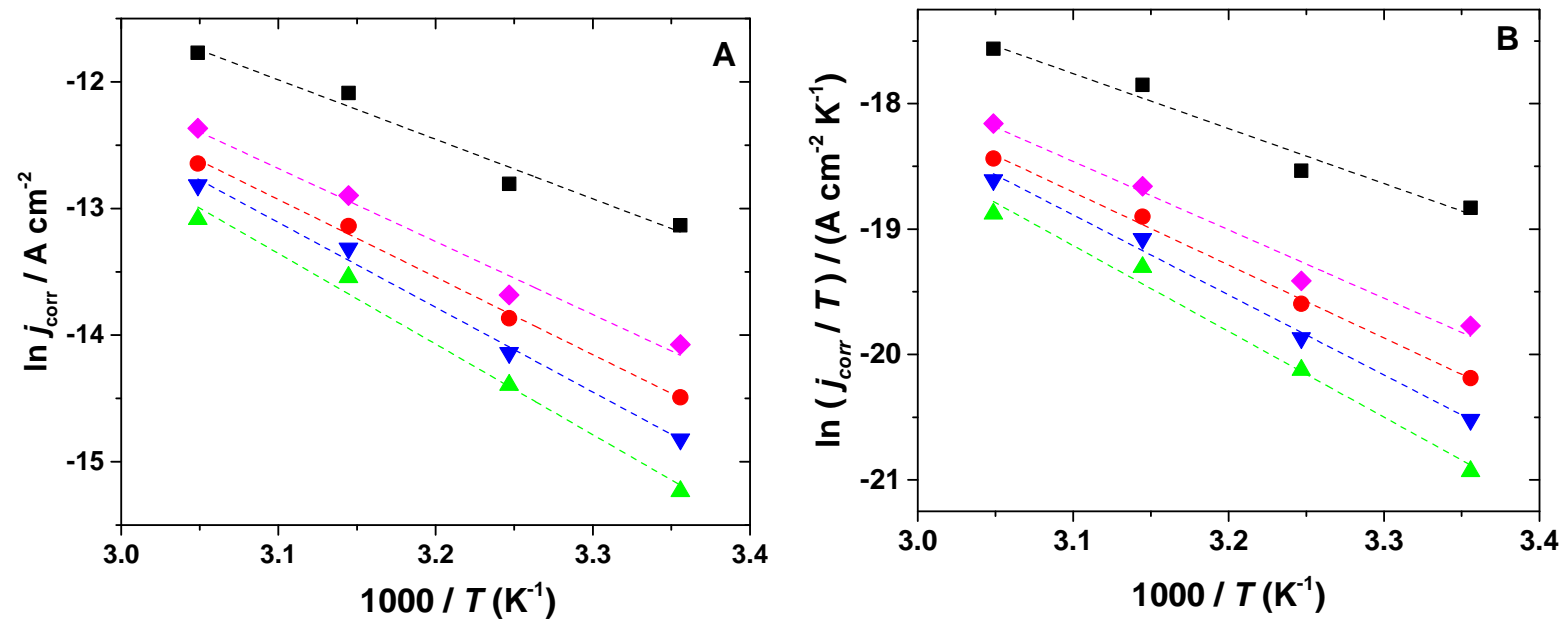

Figure 5. Arrhenius plots of $\ln \left(j_{\text {corr }}\right) v s .1 / T(\mathrm{~A})$ and of $\ln \left(j_{\text {corr }} / T\right) v s .1 / T$ (B)for bronze samples immersed in $0.2 \mathrm{~g} \mathrm{~L}^{-1} \mathrm{Na}_{2} \mathrm{SO}_{4}+0.2 \mathrm{~g} \mathrm{~L}^{-1} \mathrm{NaHCO}_{3}(\mathrm{pH}$ 5) solution without and with the addition of HCE. HCE concentration: $(\boldsymbol{\bullet}) 0,(\bullet) 0.1,(\boldsymbol{\Delta}) 0.5,(\boldsymbol{\nabla}) 0.75$, and $(\bullet) 1 \mathrm{~g} \mathrm{~L}^{-1}$. 

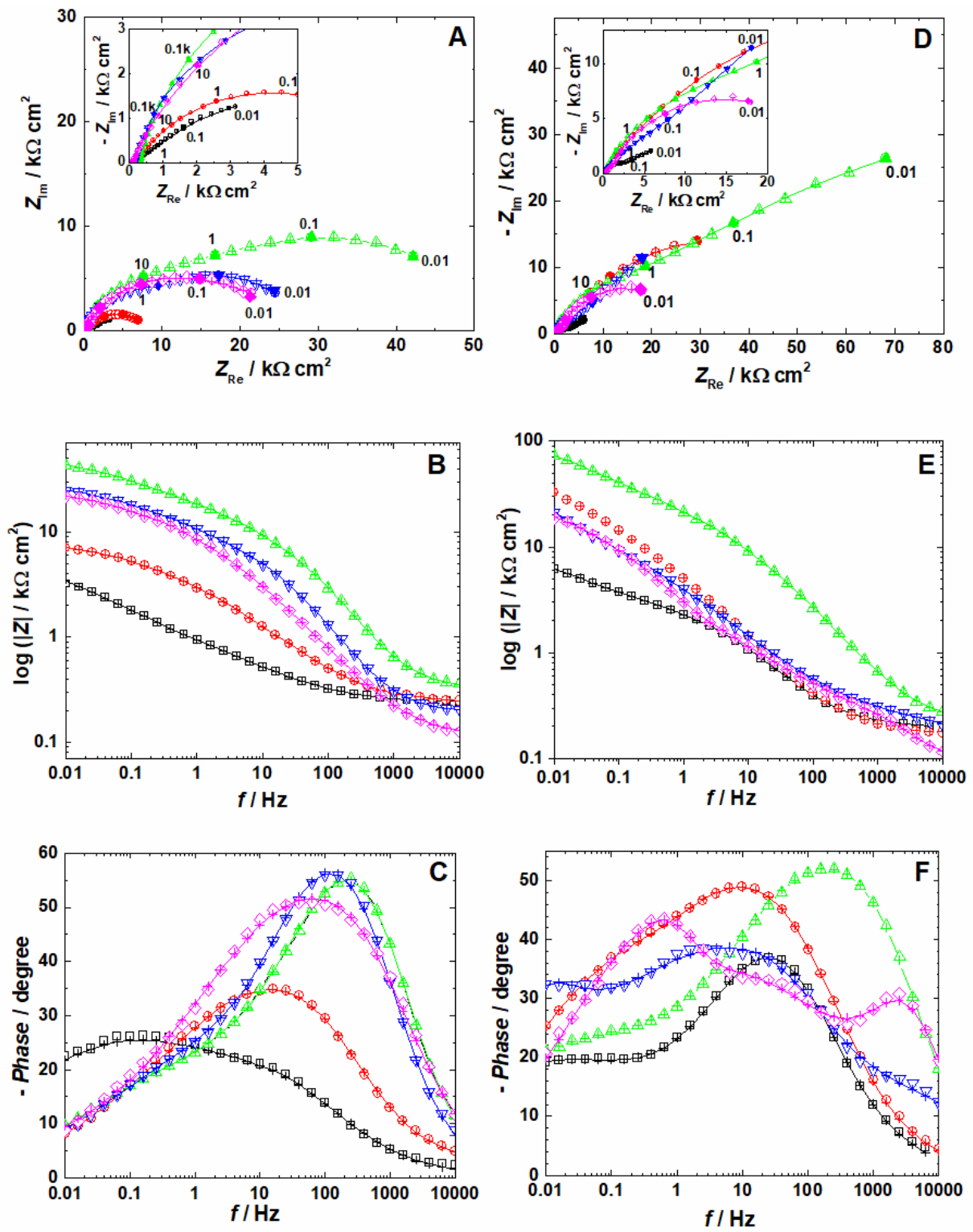

Figure 6. Nyquist plots $(A, D)$ and Bode plots $(B, C, E, F)$ recorded for bronze samples solutions after $1 \mathrm{~h}(\mathrm{~A}-\mathrm{C})$ and $14 \mathrm{~h}(\mathrm{D}-\mathrm{F})$ immersion in $0.2 \mathrm{~g} \mathrm{~L}^{-1} \mathrm{Na}_{2} \mathrm{SO}_{4}+0.2 \mathrm{~g} \mathrm{~L}^{-1} \mathrm{NaHCO}_{3}+x \mathrm{~g} \mathrm{~L}^{-1}$ HCE ( $\mathrm{pH}$ 5) solution. HCE concentrations:

$(\square) 0,(\circ) 0.1,(\Delta) 0.5,(\nabla) 0.75$ and $(\diamond) 1 \mathrm{~g} \mathrm{~L}^{-1}$.

Symbols correspond to measured data, and solid lines to the simulated results using the equivalent circuits depicted in Figure 7. The numbers in Nyquist diagrams refer to frequency in 


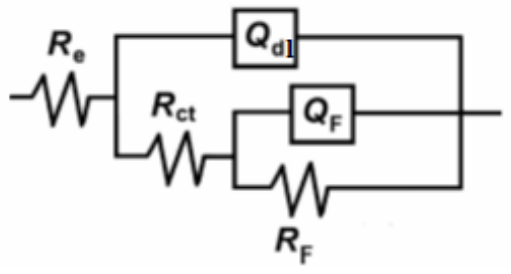

A

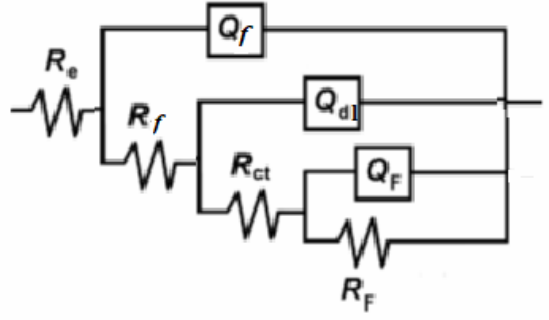

B

Figure 7. Equivalent electrical circuits used to fit the experimental impedance spectra containing: (A) 2 and (B) 3 time constants. 


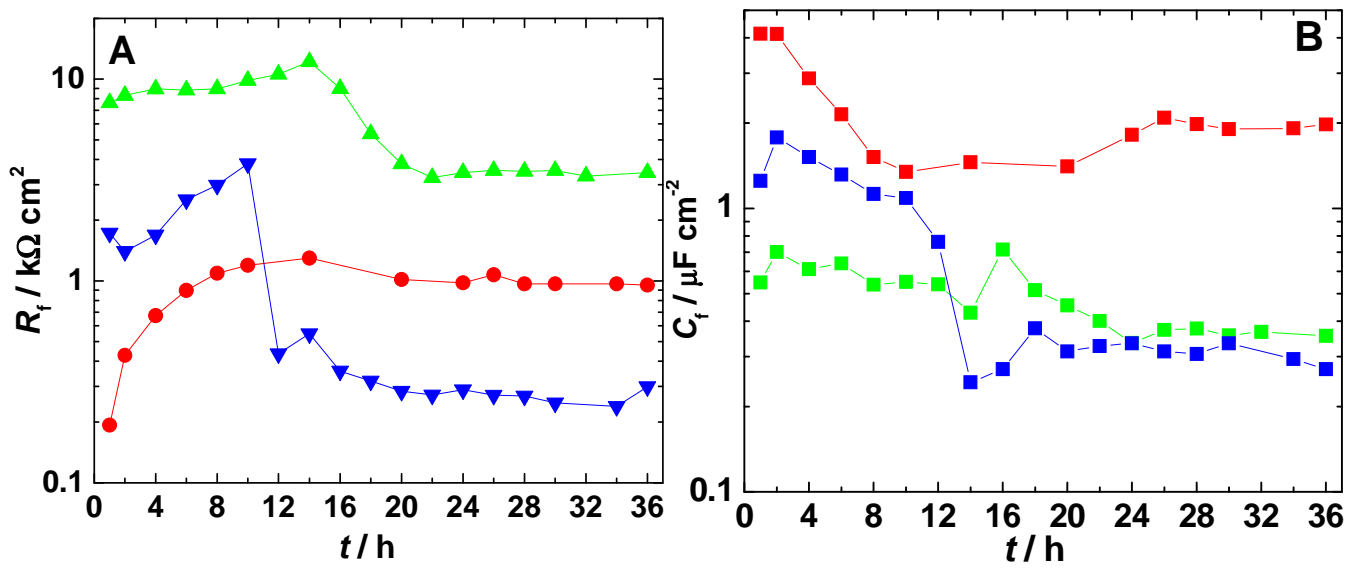

1088
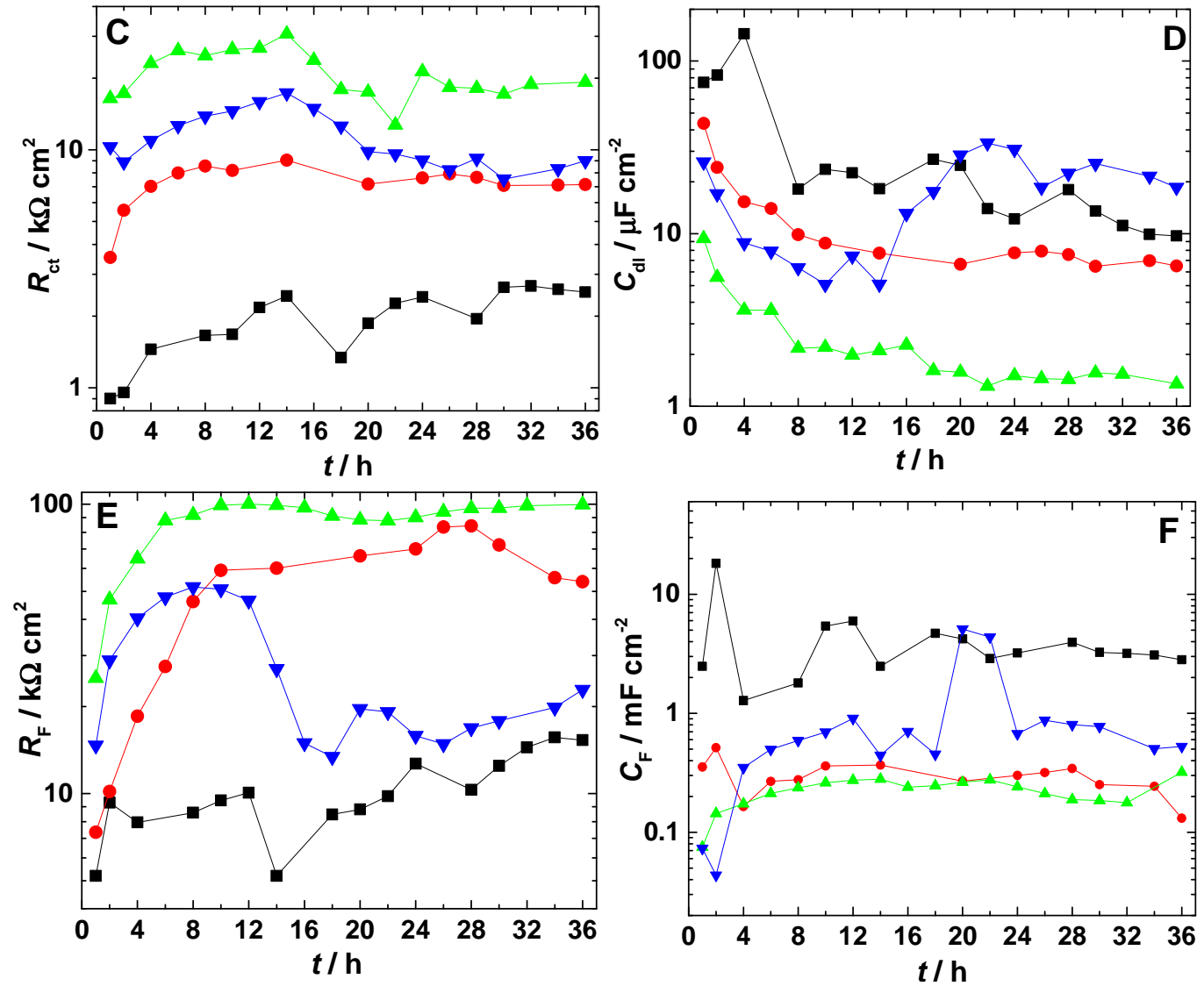

1090

Figure 8. Time evolution of the electrochemical impedance parameters of bronze corrosion during immersion in $0.2 \mathrm{~g} \mathrm{~L}^{-1} \mathrm{Na}_{2} \mathrm{SO}_{4}+0.2 \mathrm{~g} \mathrm{~L}^{-1} \mathrm{NaHCO}_{3}+x \mathrm{~g} \mathrm{~L}^{-1} \mathrm{HCE}(\mathrm{pH} 5)$ solution. HCE concentrations: $(\boldsymbol{\bullet}) 0,(\bullet) 0.1,(\boldsymbol{\Delta}) 0.5$, and $(\boldsymbol{\nabla}) 0.75 \mathrm{~g} \mathrm{~L}^{-1}$. 

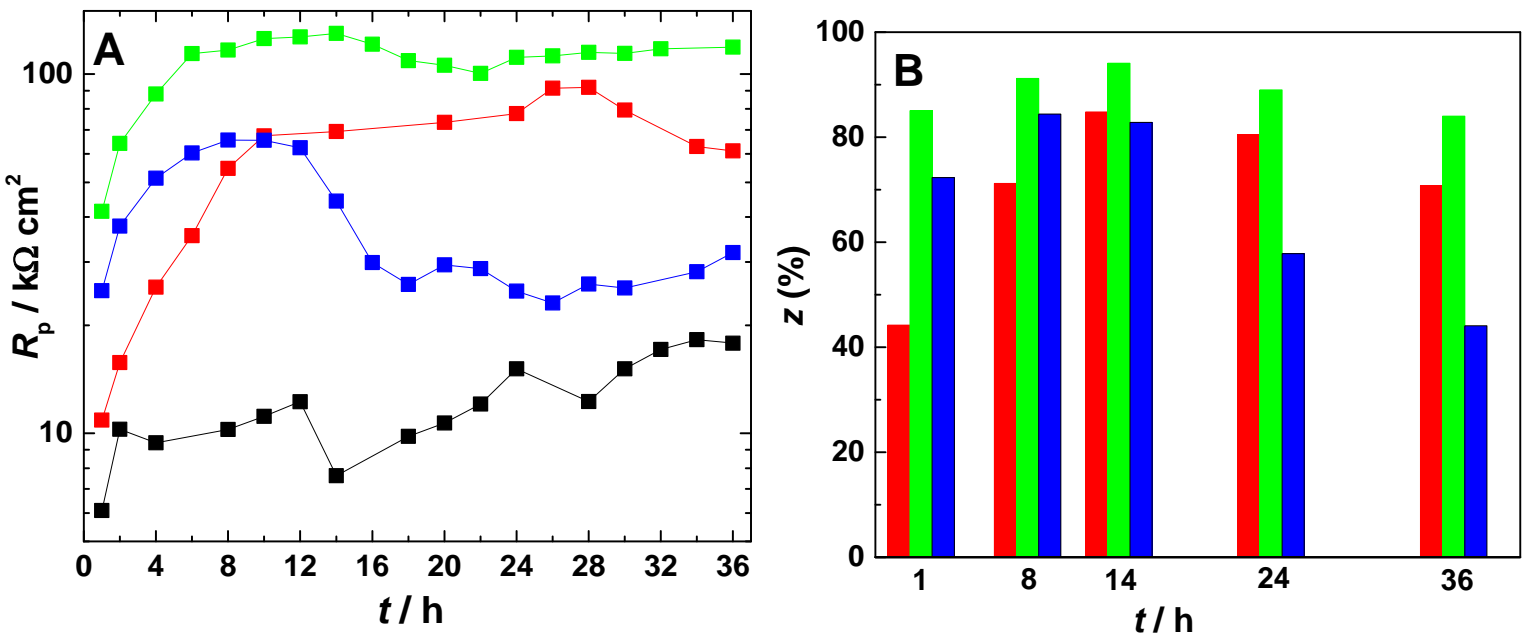

Figure 9. Time evolution of (A) the polarisation resistance and (B) the inhibition efficiency for bronze samples during immersion in $0.2 \mathrm{~g} \mathrm{~L}^{-1} \mathrm{Na}_{2} \mathrm{SO}_{4}+0.2 \mathrm{~g} \mathrm{~L}^{-1} \mathrm{NaHCO}_{3}+x \mathrm{~g} \mathrm{~L}^{-1} \mathrm{HCE}(\mathrm{pH} 5)$

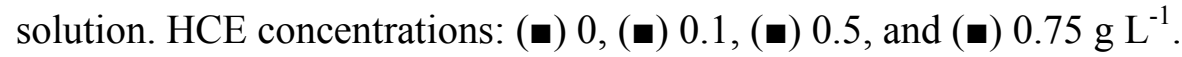
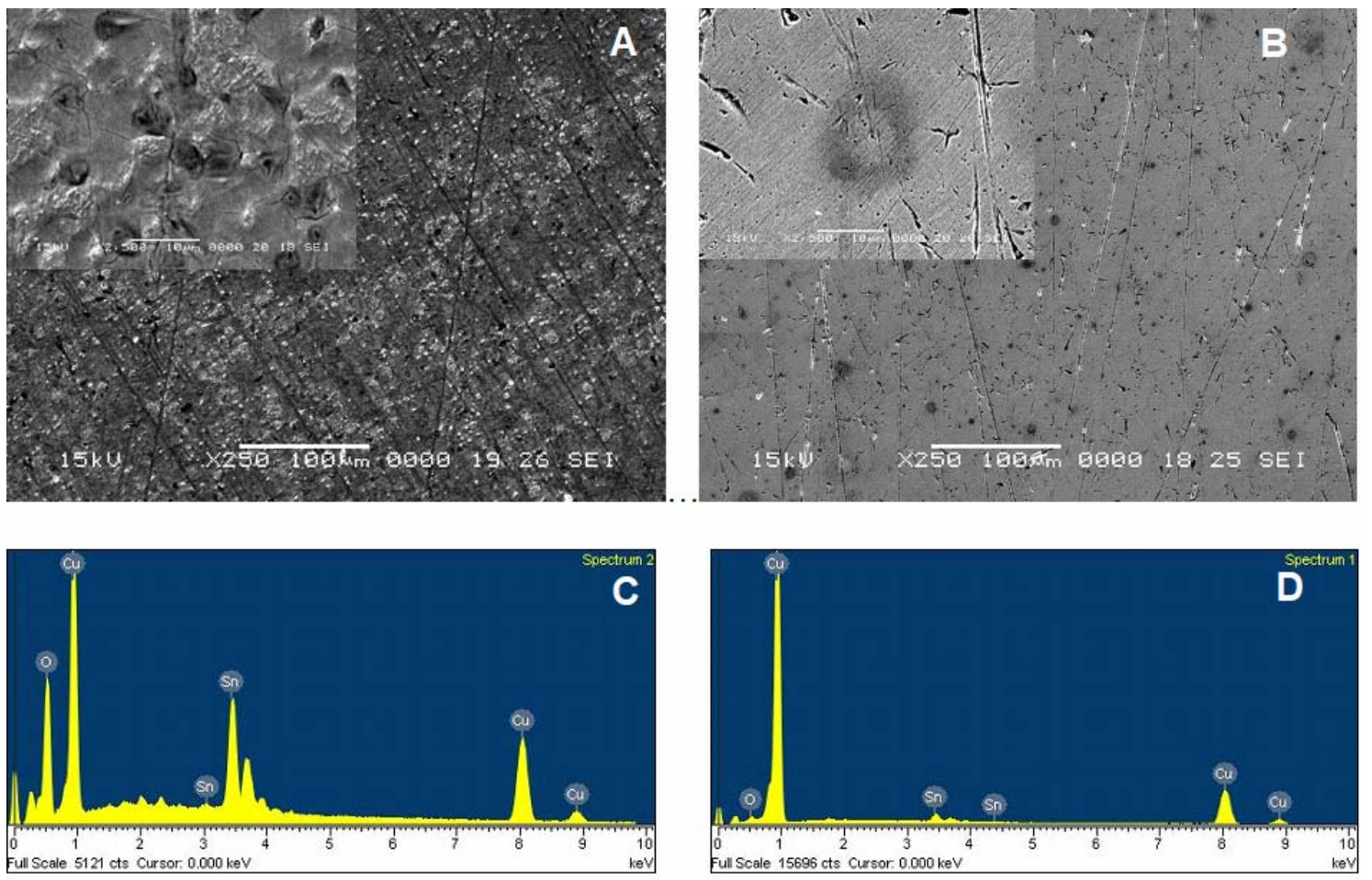

Figure 10. (A,B) SEM micrographs and (C,D) EDS analysis of bronze samples retrieved from $0.2 \mathrm{~g} \mathrm{~L}^{-1} \mathrm{Na}_{2} \mathrm{SO}_{4}+0.2 \mathrm{~g} \mathrm{~L}^{-1} \mathrm{NaHCO}_{3}$ (pH 5) solution after $36 \mathrm{~h}$ exposure: (A,C) in the absence, and (B,D) in the presence of $0.5 \mathrm{~g} \mathrm{~L}^{-1} \mathrm{HCE}$. 

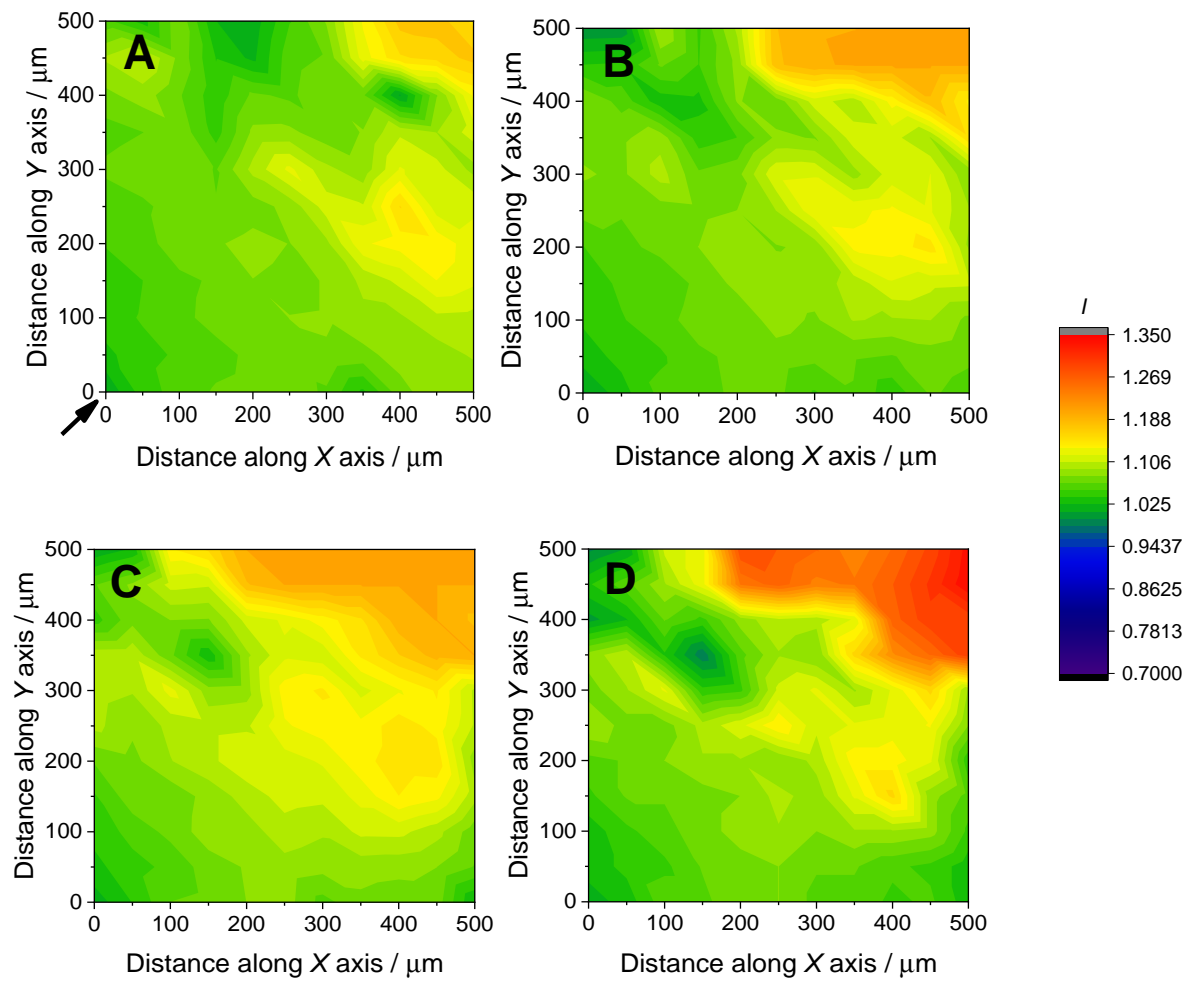

Figure 11. SECM maps of a bronze surface imaged in $0.2 \mathrm{~g} \mathrm{~L}^{-1} \mathrm{Na}_{2} \mathrm{SO}_{4}+0.2 \mathrm{~g} \mathrm{~L}^{-1} \mathrm{NaHCO}_{3}(\mathrm{pH}$ 5) solution after: (A) 23, (B) 50, (C) 70, and (D) $140 \mathrm{~min}$ immersion. Tip-to-substrate distance: $15 \mu \mathrm{m}$. Tip potential: $+0.50 \mathrm{~V}$ vs. $\mathrm{Ag} / \mathrm{AgCl} / \mathrm{KCl}$ (sat.). The sample was left unbiased at its spontaneous OCP. The arrow in (A) indicates the location selected for recording the $Z$-approach curves shown in Figure 13A. 

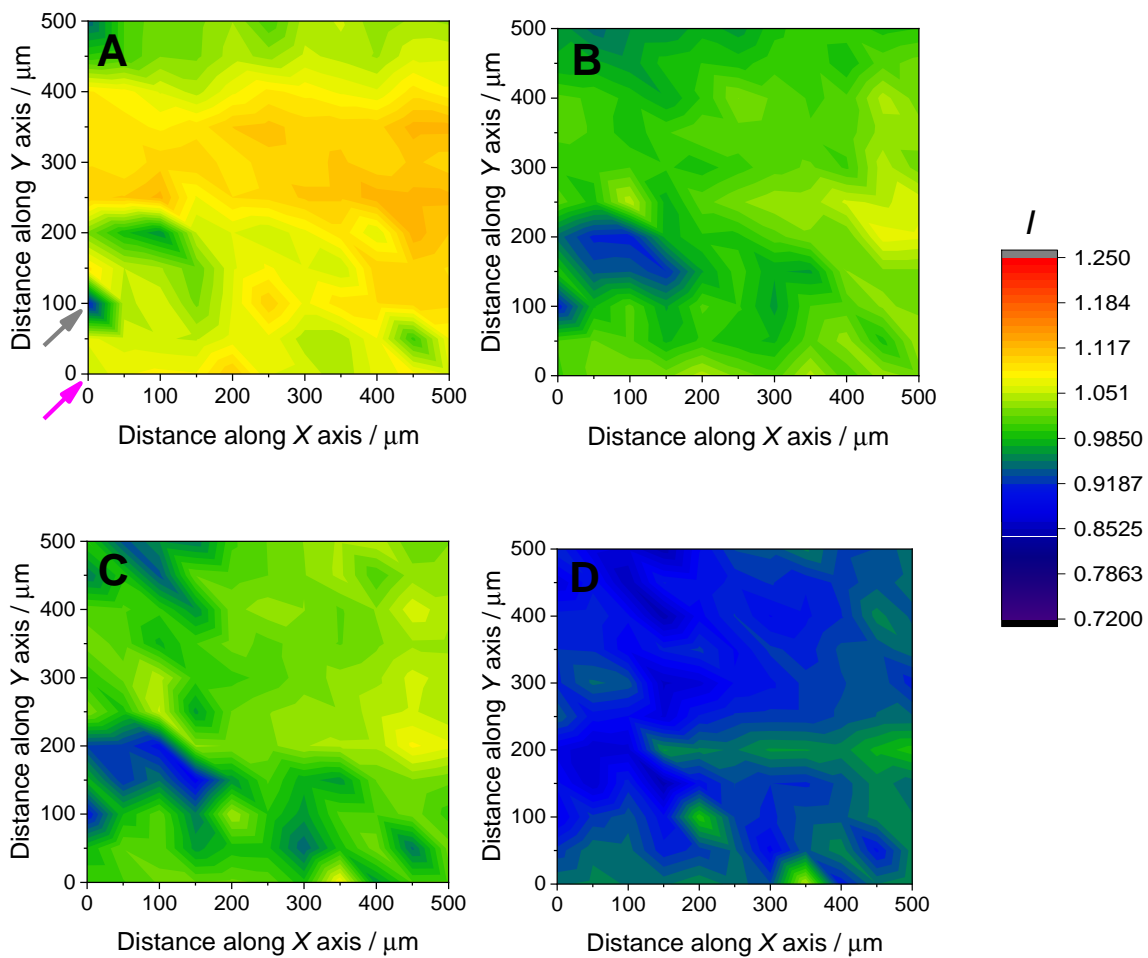

Figure 12. SECM maps of a bronze surface imaged in $0.2 \mathrm{~g} \mathrm{~L}^{-1} \mathrm{Na}_{2} \mathrm{SO}_{4}+0.2 \mathrm{~g} \mathrm{~L}^{-1} \mathrm{NaHCO}_{3}+$ $0.2 \mathrm{~g} \mathrm{~L}^{-1} \mathrm{HCE}$ (pH 5) solution after: (A) 29, (B) 42, (C) 70, and (D) $150 \mathrm{~min}$ immersion. Tip-tosubstrate distance: $15 \mu \mathrm{m}$. Tip potential: $+0.50 \mathrm{~V}$ vs. $\mathrm{Ag} / \mathrm{AgCl} / \mathrm{KCl}$ (sat.). The sample was left unbiased at its spontaneous OCP. The arrows in (A) indicate the locations selected for recording the $Z$-approach curves shown in Figure 13B (purple) and Figure 13C (grey). 

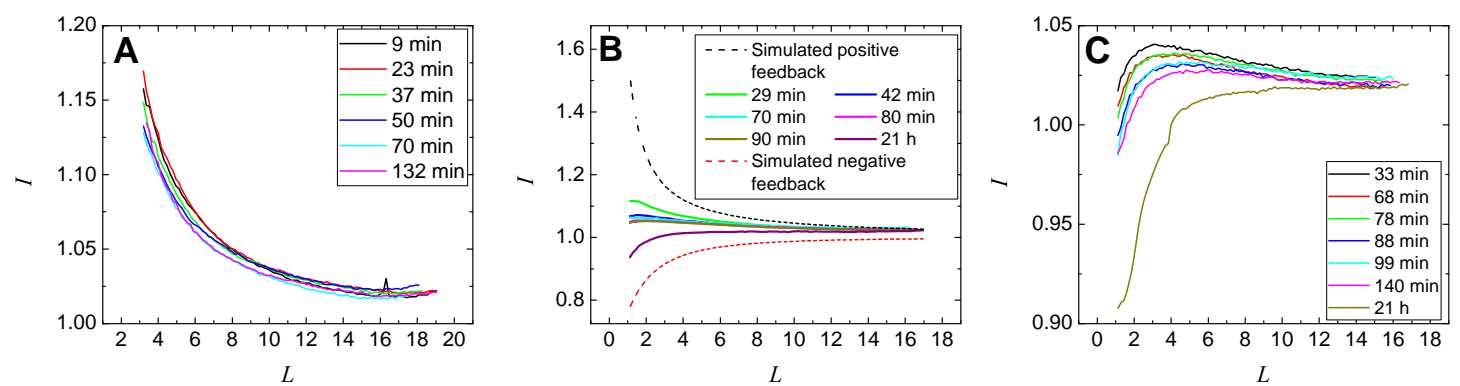

Figure 13. Normalized SECM $Z$-approach curves measured over bronze surfaces immersed in $0.2 \mathrm{~g} \mathrm{~L}^{-1} \mathrm{Na}_{2} \mathrm{SO}_{4}+0.2 \mathrm{~g} \mathrm{~L}^{-1} \mathrm{NaHCO}_{3}+x \mathrm{~g} \mathrm{~L}^{-1} \mathrm{HCE}$ (pH 5) solution. HCE concentrations: (A) 0 , and $(\mathrm{B}, \mathrm{C}) 0.5 \mathrm{~g} \mathrm{~L}^{-1}$. The actual locations at the surface of the bronze samples are indicated with arrows in: (A) black arrow in Figure 11A, (B) purple arrow in Figure 12A, and (C) grey arrow in Figure 12A. Tip potential: $+0.50 \mathrm{~V}$ vs. $\mathrm{Ag} / \mathrm{AgCl} / \mathrm{KCl}$ (sat.). Scan rate: $1 \mu \mathrm{m} \mathrm{s}^{-1}$. Legend indicates the immersion time elapsed in test solution. The $X$ axis gives the normalized distance $L=d / a$, where $d$ is the absolute distance along the $Z$ axis, and $a$ is the radius of the Pt microelectrode. 

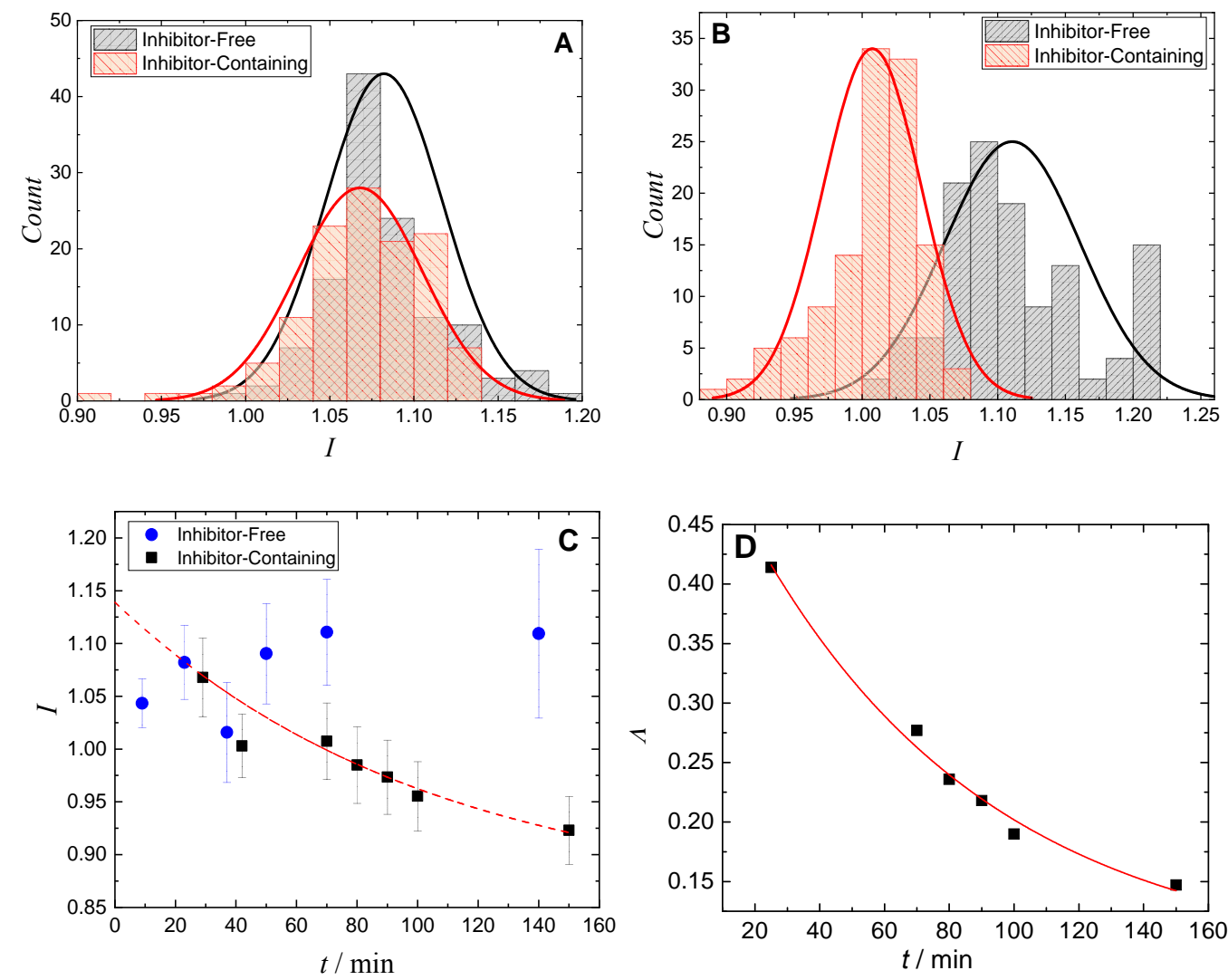

Figure 14. (A,B) Typical histograms derived from the SECM scans recorded for bronze samples immersed in $0.2 \mathrm{~g} \mathrm{~L}^{-1} \mathrm{Na}_{2} \mathrm{SO}_{4}+0.2 \mathrm{~g} \mathrm{~L}^{-1} \mathrm{NaHCO}_{3}+x \mathrm{~g} \mathrm{~L}^{-1} \mathrm{HCE}(\mathrm{pH} 5, x=0 ; 0.5)$ solution for: (A) 23-29 and (B) $70 \mathrm{~min}$. (C) Time evolution of the (C) average limiting current value from the Gaussian distributions in the histograms and (D) resulting adimensional kinetic constant. Error bars in (C) account for the standard deviations $\sigma$ of the Gaussian fits. 
Table 1. Molecular structures of the main components of HCE identified using GC-MS, and relative peak area in the GC-MS spectrum.

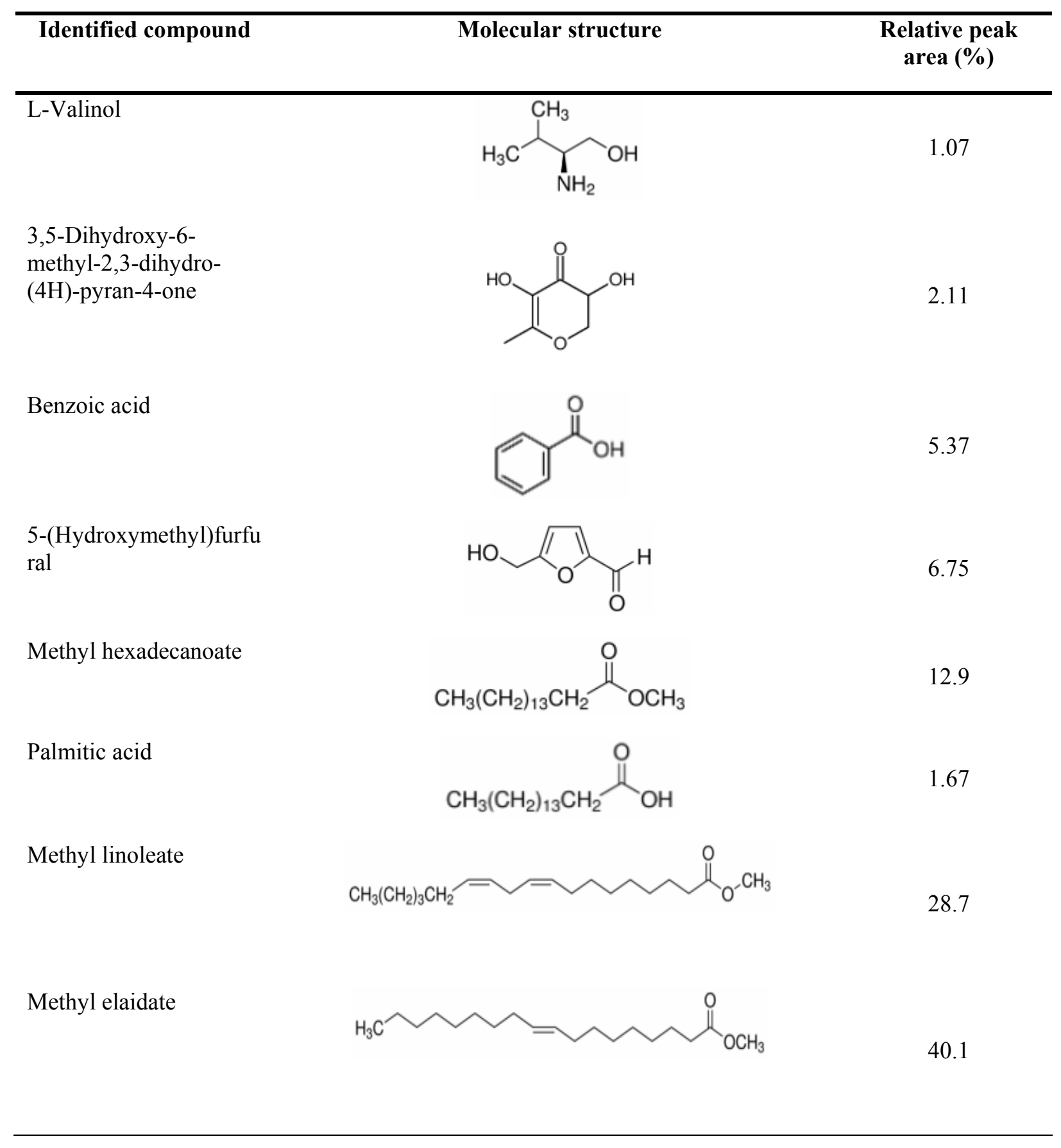


1142 Table 2. Molecular structure and concentration of the main phenolic acid and flavonoid compounds

1143 identified in horse chestnut (Aesculus hippocastanum) extract by HPLC- PDA.

\begin{tabular}{|c|c|c|c|c|c|}
\hline No. & $\begin{array}{l}\text { Identified } \\
\text { Compound }\end{array}$ & $\begin{array}{l}\text { Retention } \\
\text { time (min) }\end{array}$ & $\begin{array}{c}\text { Concentration } \\
\text { (ppm) }\end{array}$ & $\begin{array}{c}\text { Similarity } \\
\text { with standard }\end{array}$ & $\begin{array}{c}\text { Molecular } \\
\text { structure }\end{array}$ \\
\hline 1 & $\begin{array}{l}\text { Protocatechuic acid } \\
(3,4-d i h y d r o x y b e n z o i c ~ a c i d)\end{array}$ & 11.3 & 10.03 & 0.996 & \\
\hline 2 & $\begin{array}{l}\text { Myricitrin } \\
\text { (Myricetin-3-rhamnozide) }\end{array}$ & 28.6 & 45.39 & 0.998 & \\
\hline 3 & $\begin{array}{l}\text { Isoquercitrin } \\
\text { (Quercetin-3-glucozide) }\end{array}$ & 29.7 & 114.99 & 0.996 & \\
\hline 4 & $\begin{array}{l}\text { Rutin } \\
\text { (Quercetin rhutinozide) }\end{array}$ & 30.07 & 43.79 & 0.997 & \\
\hline 5 & $\begin{array}{l}\text { Quercitrin } \\
\text { (Quercetin-3-rhamnozide) }\end{array}$ & 30.9 & 89.69 & 0.995 & \\
\hline 6 & Quercetin & 37.7 & 2.18 & 0.999 & \\
\hline 7 & Kaempferol & 42.2 & 1.81 & 0.998 & \\
\hline
\end{tabular}


1145 Table 3. Corrosion parameters for bronze immersed in $0.2 \mathrm{~g} \mathrm{~L}^{-1} \mathrm{Na}_{2} \mathrm{SO}_{4}+0.2 \mathrm{~g} \mathrm{~L}^{-1} \mathrm{NaHCO}_{3}+x \mathrm{~g} \mathrm{~L}^{-1}$ $1146 \mathrm{HCE}(\mathrm{pH} 5)$ solution at $298 \mathrm{~K}$.

\begin{tabular}{|c|c|c|c|c|c|}
\hline$C_{\mathrm{HCE}} / \mathrm{g} \mathrm{L}^{-1}$ & $\begin{array}{c}E_{\text {corr }} / \\
\text { V vs. SCE }\end{array}$ & $j_{\text {corr }} / \mu \mathrm{A} \mathrm{cm}{ }^{-2}$ & $\begin{array}{c}\left|\boldsymbol{\beta}_{\mathbf{c}}\right| / \\
\mathbf{m V} \operatorname{dec}^{-1}\end{array}$ & $\begin{array}{c}\boldsymbol{\beta}_{\mathrm{a}} / \\
\mathbf{m V} \mathbf{d e c}^{-1}\end{array}$ & $Z(\%)$ \\
\hline 0 & -42.9 & 2.00 & 186.8 & 34.4 & - \\
\hline 0.1 & -16.5 & 0.51 & 186.2 & 64.1 & 74.5 \\
\hline 0.5 & -19.9 & 0.25 & 175.3 & 95.4 & 87.5 \\
\hline 0.75 & -65.2 & 0.37 & 186.2 & 54.5 & 81.7 \\
\hline 1 & -76.2 & 0.77 & 200.7 & 84.5 & 61.5 \\
\hline
\end{tabular}


1148 Table 4. Corrosion parameters for bronze immersed in $0.2 \mathrm{~g} \mathrm{~L}^{-1} \mathrm{Na}_{2} \mathrm{SO}_{4}+0.2 \mathrm{~g} \mathrm{~L}^{-1} \mathrm{NaHCO}_{3}+x \mathrm{~g} \mathrm{~L}^{-1}$ 1149 HCE $(\mathrm{pH} 5)$ solution at various temperatures.

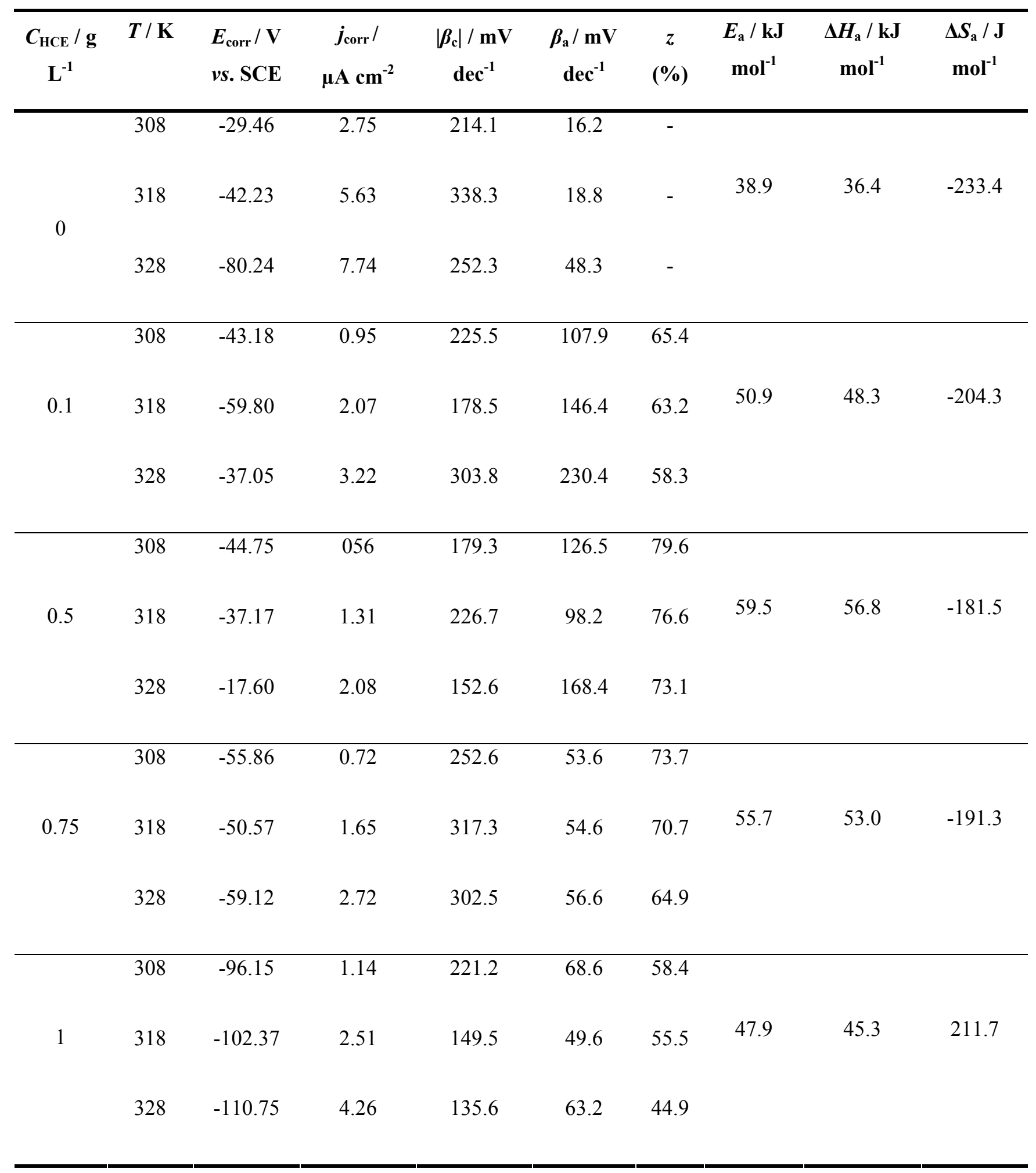


Table 5. Time evolution of the estimated kinetic constant rates for the electron transfer reaction of a 1151 bronze sample immersed in $0.2 \mathrm{~g} \mathrm{~L}^{-1} \mathrm{Na}_{2} \mathrm{SO}_{4}+0.2 \mathrm{~g} \mathrm{~L}^{-1} \mathrm{NaHCO}_{3}+0.5 \mathrm{~g} \mathrm{~L}^{-1} \mathrm{HCE}$ (pH 5). They were 1152 determined from the $Z$-approach curves shown in Figure 12B.

\begin{tabular}{ccccccc}
\hline$t$ & $29 \min$ & $42 \mathrm{~min}$ & $70 \min$ & $80 \mathrm{~min}$ & $90 \mathrm{~min}$ & $21 \mathrm{~h}$ \\
\hline$k \times 10^{3} / \mathrm{s}^{-1}$ & 7.3 & 5.2 & 4.9 & 4.5 & 4.4 & 2.1 \\
\hline
\end{tabular}

1153 